\title{
El mercado de harina de maíz en México. Una interpretación microeconómica
}

The corn flour market in Mexico. A microeconomic interpretation

\section{Gustavo Vargas Sánchez *}

\begin{abstract}
Palabras clave
Microeconomía, Mercado y formación de precios,

Empresa, Estructura de mercado, Estudio de caso

*Profesor de la Facultad de Economía de la unam. Profesor Titular C de tiempo completo.

Academia de Teoría Económica y Empresa

Correo: vargassanchez01@live.com.mx
\end{abstract}

Key words

Microeconomics, Market and price formation,

Enterprise, Market structure, Case study

JeL

D2, D4, L11, L22, L66 Página: http://www.economia.unam.mx/profesores/gvargas/

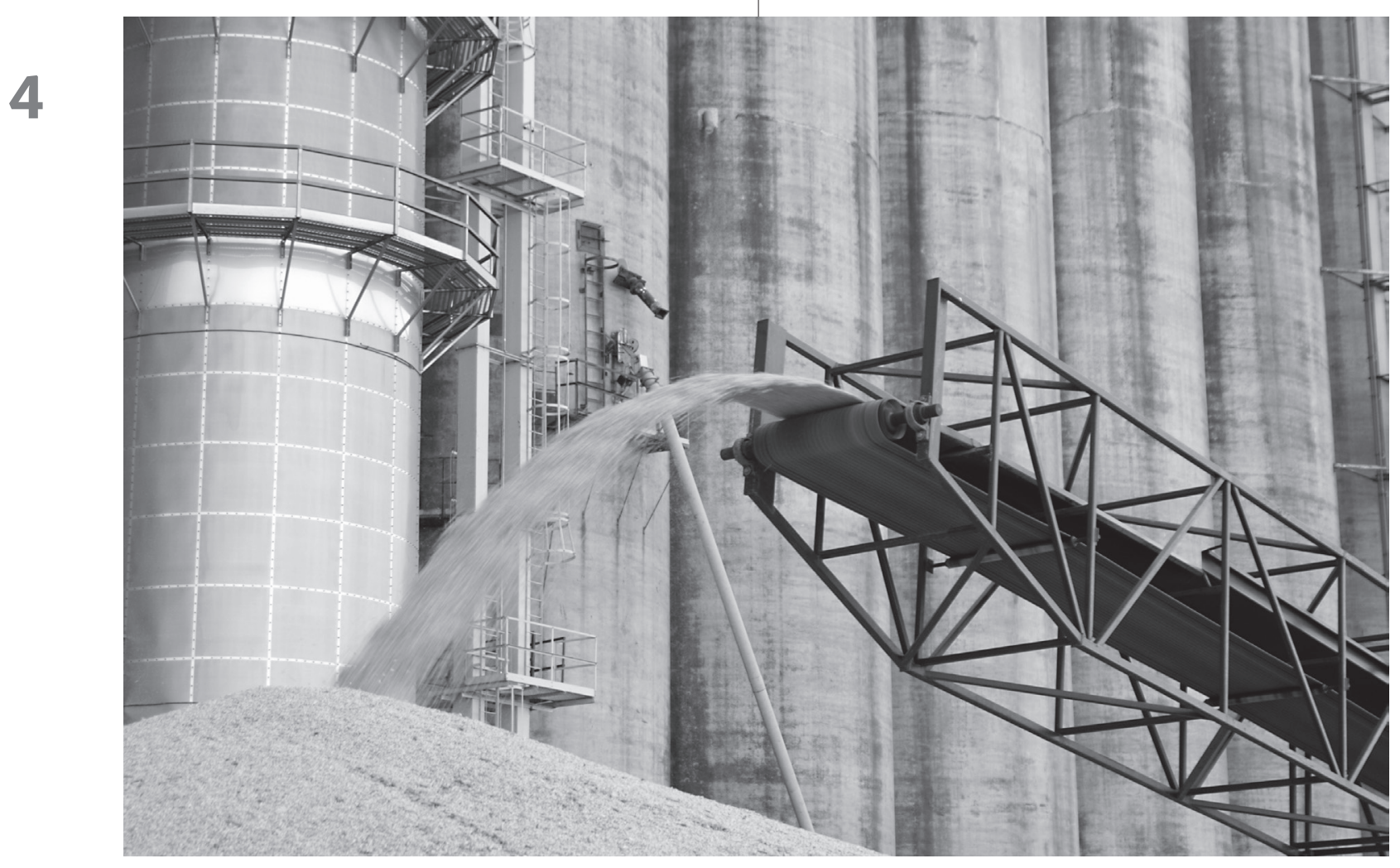

ECONOMÍA INFORMA | 405 | JULIO-AGOSTO 2017 | 
Gustavo Vargas Sánchez | El mercado de harina de maiz en México. Una interpretación microeconómica

\section{Resumen}

En este trabajo analizamos desde la perspectiva microeconómica, el mercado de la harina de maíz y su formación de precios en México. Este producto es básico en la dieta de los mexicanos, y su mercado se caracteriza por estar dominado por un duopolio: Gruma y Minsa.

Esta característica requiere que su análisis trascienda el marco teórico tradicional de la microeconomía perfecta y debe ser estudiado a partir de la teoría del oligopolio, destacando: el poder de fijación de precios, las relaciones de interdependencia y la competencia no-precio.

Este mercado está dominado por Gruma, una multinacional mexicana que opera como líder, mientras que Minsa actúa como seguidora. Una de las estrategias de barreras de entrada es la capacidad instalada, que supera la demanda nacional. Esto implica que las empresas trabajan con exceso de capacidad. Estas características: poder de fijación de precios, exceso de capacidad instalada y fluctuaciones de la demanda se intentan sistematizar en un sistema microeconómico, el cual explica las fluctuaciones de la demanda efectiva frente a una oferta potencial rígida a corto plazo y sus efectos sobre el empleo y la ocupación de los recursos productivos alrededor del fabricación de harina de maíz.

\section{Abstract}

In this paper we analyze from the microeconomics perspective, the maize flour market and its price formation in Mexico.

This product is basic in the diet of Mexicans, and its market is characterized by being dominated by a duopoly: Gruma and Minsa. This characteristic requires that its analysis transcend the traditional theoretical framework of perfect microeconomics and must be studied from the theory of oligopoly, highlighting: its power to fix prices, relationships of interdependence and non-price competition.

This market is dominated by Gruma, which is a multinational Mexican corporation that operates as a leader, while Minsa acts as a follower. One of the strategies of barriers to entry is installed capacity, which surpasses the national demand. This implies that companies work with excess capacity.

These characteristics: pricing power, excess installed capacity and demand fluctuations are attempted to be systematized as a microeconomic system, explains the fluctuations of effective demand against a rigid potential supply in the short term, and its effects on employment and occupation of productive resources around the manufacture of corn flour.
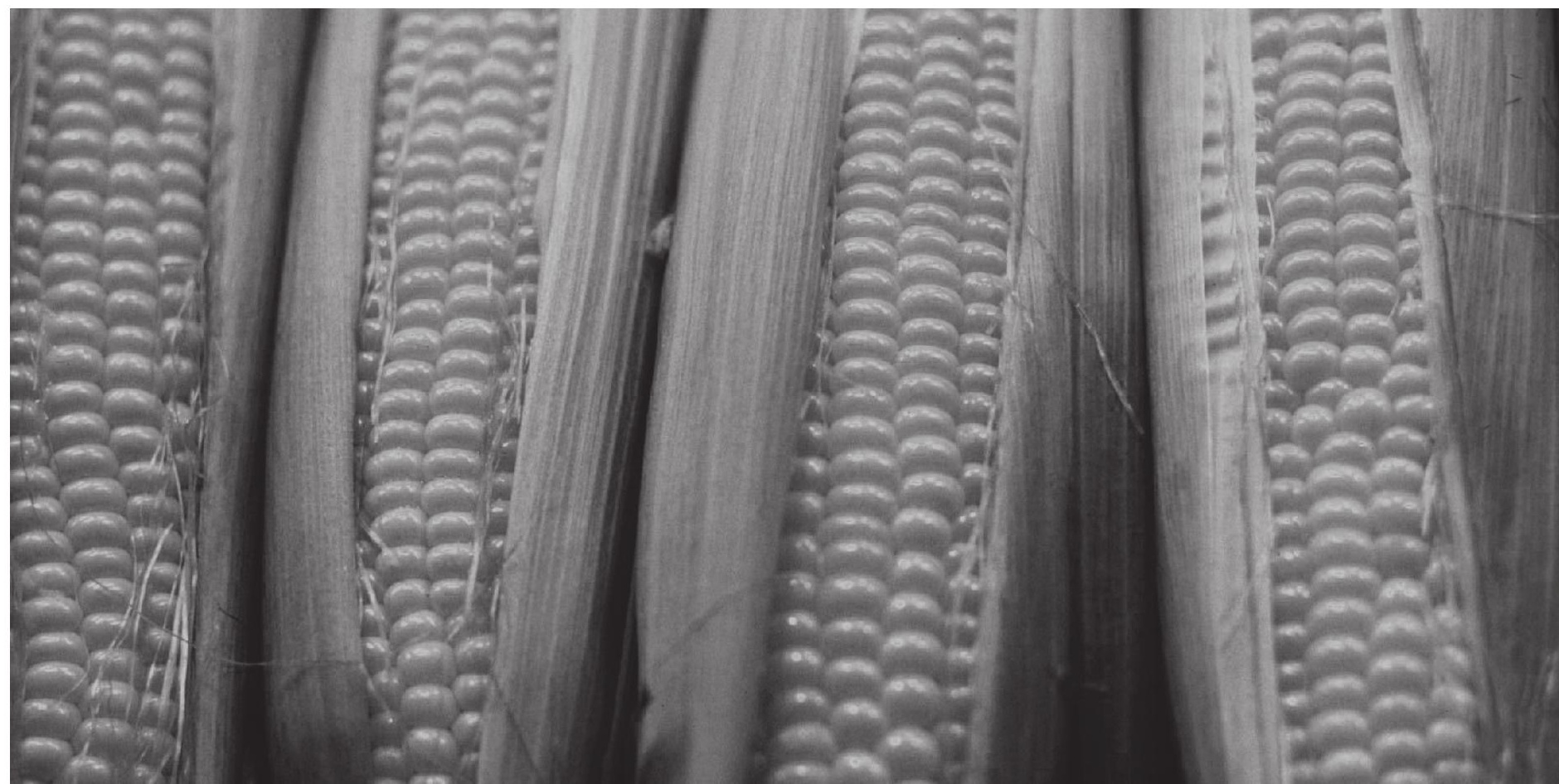


\section{Introducción}

El mercado de harina de maíz y de la tortilla posee gran importancia para la economía mexicana y para los mexicanos, entre otras características por que: en primer lugar, es un alimento básico en la dieta de las familias mexicanas; en segundo lugar, a nivel cultural y social tiene un valor estratégico; en tercer lugar, genera una gran cantidad de empleos y valor de la producción, y en cuarto lugar, en términos macroeconómicos es un bien estratégico para la estabilidad y el control de la inflación. En términos de la teoría microeconómica, como trataremos de mostrar a continuación es un buen caso de análisis.

El objetivo general de este ensayo es caracterizar el mercado de la harina de maíz en México, en particular se propone una explicación microeconómica del mercado de la harina y de la determinación de precios por la empresa líder en el mercado de este producto: Gruma.

El artículo inicia con una caracterización del mercado relevante, el contexto, la oferta y la demanda, se calculan y analizan las elasticidades de la demanda de harina de maíz. En segundo lugar, se ofrece un acercamiento a las formas de competencia y se presenta un análisis microeconómico del mercado. Finalmente, se aborda el tema de los precios, costos y beneficios, en el mercado, y una interpretación de fijación de los precios por parte de Gruma.

Características del mercado de harina de maíz en México

El mercado y la industria de harina de maíz no existía antes de los cincuenta ni en México ni en el mundo. Estos son relativamente recientes, fueron creados con la formación de la empresa mexicana Gruma en 1949 y se desarrollaron nacional y mundialmente en la década de los cincuenta y los sesenta teniendo como contexto nacional el modelo de desarrollo estabilizador o por sustitución de importaciones. En este mercado no se observó un proceso de sustitución de importables, pues no existía esta industria en México ni en el extranjero, pero si un proceso de industrialización de la harina de maíz.

El contexto económico del crecimiento del mercado de la harina es uno de los determinantes de la dinámica microeconómica y de la evolución del mercado de la harina. La evolución de la economía mexicana, en general, ha seguido las siguientes grandes etapas: la del crecimiento industrializador de los cincuentas y hasta los años 70 y su transición por la década perdida de los 80, para llegar a partir de los noventa a un periodo de crecimiento errático y pasmado que llega hasta nuestros días. Esta evolución se refleja en el dinamismo del mercado y de las estrategias de Gruma, así como de sus seguidoras.

El nacimiento de la empresa Gruma (entonces Maseca) ocurrió precisamente en medio del desarrollo estabilizador e industrialización en México y se benefició del mismo. La inexistencia del mercado de la harina de maíz, exigió que la empresa creara su propia demanda, previamente existía la demanda de nixtamal y de masa fresca, y la maquinaria y equipo que estaba relacionada con estas actividades, pero no había maquinaria para la industrial de la harina de maíz. La innovación como un proceso de industrialización de la harina de maíz, exigió que los empresarios crearan la demanda de su producto, para lo cual utilizaron diferentes estrategias, una de ellas fue comprar tortillerías con objeto de asegurar una demanda constante, esto fue útil, mientras a nivel nacional se lograba la sustitución de la masa fresca por la harina. La oferta y la demanda, y el mercado de la harina de maíz nacen en 1949. En este año, gracias a esa innovación, Maseca nace 


\section{a innovación como un proceso de industria- lización de la harina de maíz, exigió que los empresarios crearan la de- manda de su producto}

como un monopolio, el cual tuvo que formar su propio mercado, la producción y el mercado inició de cero.

El mercado de la harina de maíz refleja los cambios de la economía mexicana en el último siglo, esos cambios se expresan en la trasformación de los patrones de consumo del maíz y la tortilla. En los últimos setenta años asistimos a un proceso de conversión en el consumo de alimentos desde los preparados tradicionalmente a los fabricados industrializados, y en general hacia la comida rápida y pre-cocida, en el caso que hoy estudiamos la sustitución de la masa fresca por la harina industrializada. Este cambio tiene como telón de fondo la industrialización que vivió México a mediados del siglo pasado, la explosión poblacional de las grandes ciudades, el mercado moderno, la producción altamente tecnificada, los nuevos sistemas de comunicación, comercialización y mercadotecnia.

Desde la perspectiva del análisis microeconómico, el análisis del mercado nos lleva a preguntarnos lo siguiente: ¿estos mercados son hoy de tipo competitivo u oligopólico?, ¡el funcionamiento del mercado y la determinación de los precios es resultado de los ajustes entre demanda y oferta?, o si éste mercado es oligopólico, ¿la interdependencia de los juga- dores es a través del mecanismo de precios y las cantidades?, en términos de la teoría microeconómica, ¿qué puede y qué no puede decirnos la teoría del oligopolio sobre este mercado?, ¿cómo las empresas en este mercado están compitiendo?, si es por precios, ¿cómo fijan los precios los oligopolios? Estas son las preguntas a cuyas respuestas buscamos aproximarnos a continuación.

\section{Caracterización del mercado de harina de maíz en México}

Considerando la cadena de valor: maíz- harina-tortilla coexisten tres mercados: el del maíz, el de la harina de maíz y el de la tortilla. En el primero, los agricultores se pueden dividir en productores de temporal y de riego, este mercado se convierte en proveedor del insumo principal para las empresas harineras. En el segundo, la elaboración de la harina de maíz, está altamente concentrado y dominado por un duopolio formado por: Gruma la empresa líder, y Minsa (Bunge) la seguidora, ambas producen más del $90 \%$ de la harina a nivel nacional, el resto se encuentra en manos de otras empresas pequeñas. Este duopolio tienen poder de negociación frente a sus proveedores, y con la libre importación del grano pueden elegir entre comprar el maíz en el mercado nacional o en el internacional. Hacia delante de la cadena de valor, éstas corporaciones también cuentan con capacidad para determinar los precios ante un conjunto de demandantes que se pueden dividir en tres tipos: las tortillerías, otras empresas productoras de derivados y las tiendas minoristas que venden a los compradores finales. De estos mercados, nuestro sujeto de estudio es el mercado de harina. Entre otras razones porque son éstas corporaciones las que dominan las características generales de la cadena de valor. 
El mercado de harina de maíz es de tipo oligopólico, Gruma es la empresa líder y Minsa la seguidora, estas corporaciones fijan las variables relevantes del mercado, en particular: el precio y la calidad de su producto, aunque existen otras empresas dado su participación marginal, podemos tratar a este mercado como un duopolio. El producto en el mercado de la harina de maíz lo podemos definir como homogéneo, las diferencias entre la harina que produce Gruma, y Minsa son mínimas, casi se reducen a su presentación. Tradicionalmente los precios de la primera son superiores a los de sus rivales, la diferenciación se logra principalmente a través de la mercadotecnia y publicidad, así como de las redes de distribución y la existencia en los anaqueles de los vendedores. Esto significa que la competencia no es por precios, la empresa líder fija sus precios y la seguidora acomoda los suyos por debajo de los de la líder.

Dadas las características en los mercados de harina de maíz, es prudente poner distancia a la idea de que es el mercado el que fija precios por el libre juego de la oferta y la demanda. Se debe explorar formas diferentes de mercado ${ }^{1} y$ de cómo la empresa fija precios, la magnitud de sus márgenes de ganancia y la cantidad demandada de su producto. La dinámica de los mercados, y las relaciones que se observan en este mercado trascienden las ideas de los manuales de microeconomía que consideran que los precios se forman por la oferta y la demanda. Las relaciones observadas se han de ubicar en términos de los mercados con comportamiento de tipo oligopólico, donde tienen lugar estrategias de inversión, de desarrollo tecnológico, de organización, de mercadotecnia y publicidad. Por ejemplo, en los últimos sesen-

1 Nos referimos a la forma más difundida de los manuales de economía, que se refieren al mercado de competencia perfecta. ta años, en el mercado de la harina de maíz el número de productores se ha concentrado, los procesos de producción de la harina se han transformado de forma gradual pero sostenida hacia una mayor tecnificación, el resultado es una industria que compite utilizando las tecnologías modernas en los mercados regionales, nacionales y globales.

\section{Producción de harina de maíz}

La producción nacional de harina presenta varias etapas claramente delimitadas (gráfica 1): La primera consiste en un crecimiento hasta 1996, la segunda es una tendencia descendente que se puede ubicar de 1997 a 2004 con un ligero repunte en 2005, 2006 y 2007, la tercer etapa de un estancamiento, o lento crecimiento, inicia con una recuperación notable en 2008, pero en los años se estanca. La tasa promedio de crecimiento (simple) de la producción de harina de maíz para el periodo de 1996 a 2015 fue de $1.4 \%$. Si consideramos el crecimiento de la población (1.3\%). Podemos concluir que la característica general del mercado de la harina de maíz es de estancamiento, lo cual es de cierta manera reflejo del comportamiento de la demanda agregada nacional.

El crecimiento de la oferta de harina de maíz desde los años 50 hasta 1996 se explica por el crecimiento en la tasa de sustitución de masa fresca por la harina de maíz, el crecimiento de la población y de su ingreso, el aumento en los derivados de la tortilla. Posteriormente a 1997 el estancamiento en ese mercado también está asociado a la lentitud del crecimiento de las variables antes mencionadas y un cambio en la dieta de los consumidores. Una forma en como las empresas harineras han enfrentado este hecho es a través de estrategias de comercialización, publicidad y mercadotecnia a favor del consumo de la tortilla con base en la 
Gustavo Vargas Sánchez | El mercado de harina de maiz en México.

Una interpretación microeconómica

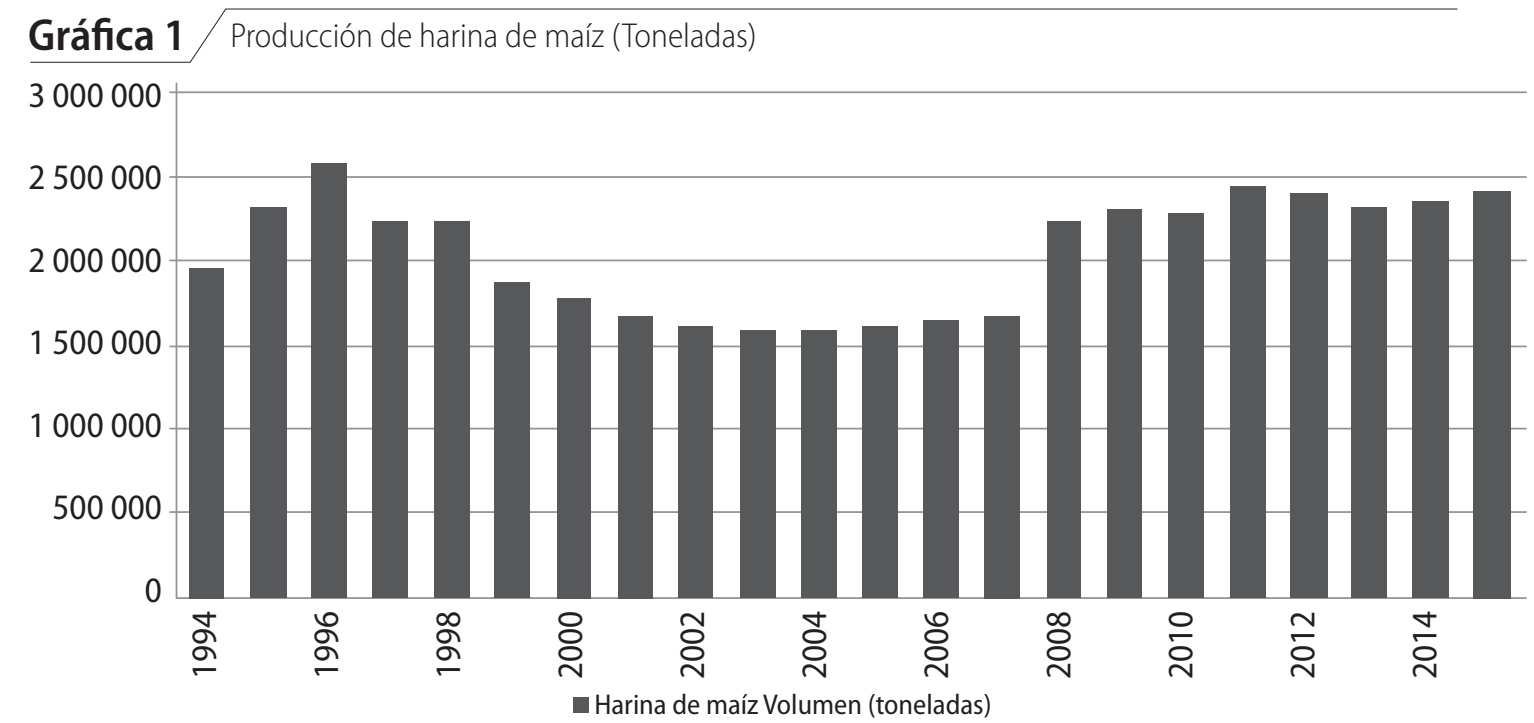

Fuente: Elaboración propia con base en INEGI. Encuesta mensual.

*A partir de 2007 se utilizó el Sistema de Clasificación Industrial de América del Norte (SCIAN) versión 2007.

harina. A pesar de estas medidas, a partir de 2010 y 2011, el desempeño y la proyección del crecimiento de este mercado para los próximos años es muy conservador. En estas condiciones y la estimación futura del mercado nacional, es comprensible la reacción de Gruma y Minsa, las cuales han buscado mercados más dinámicos, de ahí su decisión de continuar e incrementar sus inversiones en el extranjero y en sus estrategias de diversificación.

El consumo nacional aparente de harina de maíz en México presenta un crecimiento lento el cual tiende al estancamiento e incluso a la contracción. (cuadro A.1 del anexo estadístico). Se observan tres etapas: la primera, de crecimiento hasta 1996, la segunda de contracción, la cual inicia en 1997 y llega hasta 2005 cuando toca su nivel más bajo. La tercera de recuperación hasta 2012. El desempeńo en el consumo per cápita de harina de maíz es más alarmante, el cual paso de 1994 de 21.4 kilogramos a 18.8 kilogramos per cápita anuales en 2013. En síntesis, la marcha de la oferta y de la demanda de harina de maíz tiende a una situación de estancamiento y lo más crítico es el consumo por habitante, el cual se ha reducido.

La tendencia de la oferta y la demanda representa una situación crítica para las empresas harineras, en términos de su crecimiento. La reducción del consumo per cápita de harina de maíz (y de tortillas), se explica por: el estancamiento, y deterioro en el ingreso de los consumidores, el crecimiento de los precios de la harina y de las tortillas, el cambio en los patrones de consumo en las últimas décadas, (sobre todo en la ciudad, en la dieta de los jóvenes, y en los estratos sociales medio, medio alto y alto). En la demanda de estos productos está presente una dinámica contradictoria, por una parte, a nivel macro el ingreso de las clases medias bajas y bajas, (sobre todo de aquellos que están sujetos a un ingreso fijo) se está contrayendo, y por otra parte, el precio de la harina y de maíz ha aumentado sistemáticamente. Un reflejo de estas tendencias lo podemos observar en el calculo de las elasticidades que a continuación presentamos. 
Elasticidades de la demanda de harina de maíz en el mercado nacional

La harina de maíz, puede clasificarse como un bien básico (dado que es insumo en la producción de tortillas), cuya demanda no responde a las variaciones de los precios, es decir, se espera que su elasticidad precio de demanda sea inelástica (menor que uno). Hasta los ochenta y los noventa a la harina y la tortilla se consideraban como bienes Giffen por algunos economistas, ${ }^{2}$ pues aun cuando aumentaba su precio la demanda también lo hacia. La explicación que ofreció A. Marshall fue que al aumentar los precios de un producto alimenticio (la tortilla), ocurría un efecto ingreso y sustitución por el cual se reducía el consumo de otros bienes (como por ejemplo, la carne, el huevo o la leche) para continuar consumiendo tortilla, cuya demanda aumentaba sustituyendo el consumo de los otros alimentos.

El cálculo de la elasticidad precio de la demanda harina nos indica que esta es casi cero en el periodo estudiado: 0.09 y, 0.16 para la elasticidad arco. (Ver cuadro A1. En el anexo estadístico) Por lo que podemos decir que es perfectamente inelástica, y conceptualizamos como rigidez de la demanda. ${ }^{3}$ En términos

2 En microeconomía se considera que el efecto ingreso puede ser suficientemente grande para hacer que la curva de demanda de un bien tenga pendiente positiva.

3 Esta es diferente a la rigidez de los precios explicada por P. Sweezy en su modelo de la curva de demanda quebrada. En este caso la curva de la demanda tradicional si existe pero hay un punto en el cual cambian las elasticidades precio, y se abre un brecha. En esta los costos de producción pueden aumentar (o bajar) y el precio no cambia. En nuestro caso de estudio, si los costos medios aumentan los precios también lo hacen y la demanda no cambia. Pero si los costos medios bajan los precios no bajan. En todo caso se podría hablar de rigidez de precios a la baja. Sin embargo, lo que aquí se está argumentando es que por el lado de la demanda, esta no es función de los precios.

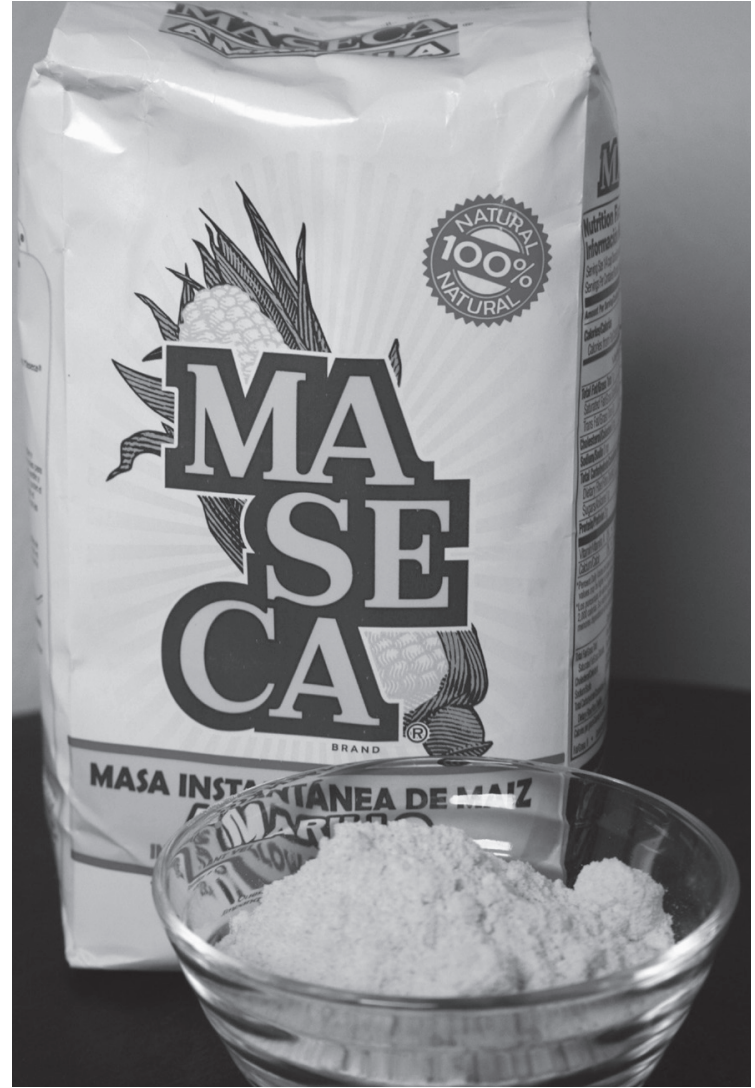

teóricos ocurren dos cosas interesantes: si bien por la elasticidad precio podemos decir que su demanda es rígida no llega a ser un bien Giffen, al menos en el agregado. La rigidez en la demanda de harina de maíz se explica porque es un bien básico, y se puede considerar además, el manejo discrecional de los precios por parte de las empresas y el estancamiento de la capacidad de compra de los consumidores. En segundo lugar, la rigidez de la demanda se convierte en una ventaja competitiva poderosa en favor de los oligopolios que pueden subir los precios sin que esto afecte la demanda de su producto.

La elasticidad ingreso de la demanda de harina de maíz es de 0.42 y la elasticidad arco es 0.18 . Esto significa que en general para los consumidores, la harina y la tortilla se comporta como un bien normal de primera necesidad, en ciertos años, y para determinados 
segmentos de la población (los más pobres) incluso puede comportarse como un bien Giffen, o también de lujo. (Véase anexo estadístico, cuadro A2.)

Mucho nos gustaría decir que conforme aumenta el salario aumenta la demanda, sin embargo, lo que se puede ver es que al considerar que el salario nominal para quienes perciben salarios o un ingreso fijo, el cual se ha estancado y se ha venido deteriorando en los últimos años, lo observable es la reducción de sus ingresos y con éstos de su consumo, incluso de bienes necesarios como la tortilla.

Al considerar ambas elasticidades es evidente que los determinantes de la demanda y del precio de la harina de maíz obedecen a criterios diferentes: por un lado, la evolución de los precios de este producto es resultado de factores estructurales: costos de su producción y de las decisiones estratégicas de las empresas harineras que gracias a su poder de mercado aumentan los precios, y por otra parte, la cantidad demandada de la harina de maíz se explica por las necesidades de los consumidores, sus ingresos, de la sustitución de masa fresca por harina de maíz, y por los cambios en los patrones de consumo en la época contemporánea, pero con todo, la tendencia en el deterioro de la capacidad de compra de los mexicanos, en general, esta es una situación delicada en términos sociales y también para las expectativas de los oferentes. Es paradójico que las políticas de corte neoliberal, al final impacten negativamente la demanda de las mismas empresas nacionales.

Estos resultados contrastan con la idea de la microeconomía tradicional que supone que la oferta y la demanda se explican por una variable común: los precios. Nuestra investigación, en cambio, nos muestra que los determinantes de las cantidades demandadas de harina y de tortillas son estructuralmente di- ferentes a los determinantes de la oferta. Para la empresa, los determinantes de los precios de su oferta están asociados a su estructura de costos (principalmente, el precio del maíz y de la mano de obra, tecnología, organización y mercadotecnia) y la rentabilidad del negocio. En tanto para los consumidores, la cantidad demandada está determinada por sus necesidades, su cultura, hábitos alimenticios, su capacidad de compra entre otros. La explicación que nos ofrece la pirámide de Maslow ${ }^{4}$ es más plausible para comprender el comportamiento de los consumidores en primer lugar con relación a sus necesidades. En todo caso el desafío en términos de la teoría micro es cómo representar estas variables en un sistema explicativo.

\section{Formas de competencia en el mercado nacional de harina de maíz}

En el mercado de la harina y de las tortillas las formas de competencia son diversas. Las relaciones de mercado son múltiples y evolucionan, la competencia de precios en los mercados oligopólicos se reducen a casos excepcionales: ${ }^{5}$ por ejemplo, en los principios de la historia de la empresa, y en modelos meramente teóricos. Lo que observamos en las relaciones de los mercados oligopólicos como el que nos ocupa son relaciones de mercado diversas, donde predomina la competencia de no precios. ${ }^{6}$ Históricamente los enfoques sobre competencia han sido:

4 La cual nos explica el comportamiento de la demanda de los bienes y servicios a partir de una jerarquía de las necesidades humanas. Abraham Maslow, A Theory of Human Motivation.

5 La competencia de precios solo es posible observarla en los modelos teóricos que suponen competencia perfecta.

6 Por ejemplo, un acercamiento a esta dinámica, utilizando el instrumental tradicional la presenta Ana Koutsoyanis en Non Prices Competition. 
La competencia de precios. ${ }^{7}$ Los precios juegan un papel muy importante, por ejemplo, en los inicios de Maseca, estrategias de precios se utilizaron para introducir la harina de maíz como sustituto de la masa fresca, y crear un estímulo para que las tortillerías en los años cincuentas encontraran más rentable el uso de este insumo. En este sentido la reducción de los precios se utilizó para persuadir a los consumidores (tortillerías), y para disputar el mercado a los productores de nixtamal y masa fresca. Como resultado de esta guerra, en los últimos sesenta años, las empresas de nixtamal han perdido una cuarta parte del mercado nacional, pero la guerra entre las empresas harineras y los molinos de masa fresca tiene un largo camino por delante. La competencia de precios puede tomar muchas formas, por ejemplo, las "ofertas" o rebajas de temporada, en el caso de Gruma esto no existe o no es frecuente.

La competencia en el mercado al menudeo de la harina de maíz se comporta diferente a como se presenta en los manuales de microeconomía, la demanda no se desplaza hacia los bienes con el precio menor en el mercado. La participación mayoritaria de Gruma en el mercado de la harina no se explica por precios menores a los de la competencia. Los precios pueden ser superiores o menores. Por ejemplo, en los mercados al medio mayoreo, (información en línea) el kilogramo de Gruma es menor (10.50 contra 11 de Minsa). En los supermercados los precios de esta companía son superiores a los fijados por su rivales. Como vemos en el siguiente cuadro 1, los pre-

7 Habrá que subrayar que la competencia de precios a que nos referimos, es la competencia empírica y observable en diferentes mercados, esta es diferente a la competencia teórica de precios de los libros de microeconomía, la cual la considera como el mecanismo de lograr el equilibrio, ya sea parcial y general de un sistema teórico. cios son semejantes o iguales en las cadenas de supermercados, pero diferentes entre las marcas, en sus anaqueles. El precio de Maseca en la presentación de un kilogramo de harina es superior a las de los otras marcas. El precio de Maseca es 12.50; Minsa es 11; Marca Aurrera es 9.50. Una de las diferencias más notables es con la Marca Aurrera, en la modalidad más económica de Walmart, donde la disimilitud es del 20\%. En algunas tiendas de supermercados, ni siquiera existen en sus anaqueles otra. Considerando a la información de la Profeco, en Quién es Quién en los precios, el promedio para la zona metropolitana: el precio de Maseca fluctúa entre $\$ 12$ y $\$ 13$ pesos y el de Minsa es de $\$ 10.5$. Las diferencias de precios es una forma de competencia la cual no implica que el mercado se vacíe con precios menores.

Competencia es de inversión e innovación estratégica. En el caso de Gruma esta es la forma de competencia dominante, la empresa ha invertido en general en desarrollar su escala y capacidad productiva, así como en su diversificación. Su estrategia de expansión ha seguido una senda de: 1 . Crecimiento orgánico invirtiendo e innovando en nuevas plantas; 2 . A través de fusiones y adquisiciones como un método más económico y eficiente de ingresar a nuevos mercados; y, 3. Alianzas estratégicas.

Inversión en escala y capacidad de producción. Esto ha tomado diferentes formas: inversión en nuevas plantas o fusionar las existentes, en zonas estratégicas con el criterio de cercanía tanto a las zonas productoras de maíz, como a los centros dinámicos de consumo de su producto. La integración vertical hacia delante, en la forma de compra de tortillerías, de sistema de distribución y comercialización. La integración horizontal, en el desarrollo de empresas y divisiones proveedoras de maquinaria, equipo, tecnología, infraestructura de instalaciones, 
Gustavo Vargas Sánchez | El mercado de harina de maiz en México.

Una interpretación microeconómica

Cuadro 1. Precios de la harina de maíz en presentación de un kilogramo

\begin{tabular}{llllll}
\hline Tienda/ Marca & $\begin{array}{l}\text { Maseca: } \\
\text { nixtamalizado }\end{array}$ & $\begin{array}{l}\text { Maseca: } \\
\text { de maíz amarillo }\end{array}$ & $\begin{array}{l}\text { Maseca } \\
\text { tamales }\end{array}$ & $\begin{array}{l}\text { Marca } \\
\text { Aurrera: }\end{array}$ & Minsa \\
\hline Bodega Aurrera & $\$ 12.50$ & - & - & $\$ 9.50$ & - \\
Walmart & $\$ 12.90$ & & $\$ 13.90$ & $\$ 9.90$ & \\
LaComer Sucursal el Olivar (Profeco) & $\$ 12.80$ & - & - & - & - \\
$\begin{array}{l}\text { Mega Comercial Mexicana la Villa } \\
\text { (Profeco) }\end{array}$ & $\$ 13.00$ & - & - & - & - \\
$\begin{array}{l}\text { Superama } \\
\text { Sumesa }\end{array}$ & $\$ 12.90$ & - & - & - & - \\
Información en línea: "Mayoreo total" & $\$ 10.50$ & - & - & - & - \\
$\begin{array}{l}\text { Chedraui } \\
\text { Profeco (Zona metropolitana) }\end{array}$ & $\$ 11.80$ & $\$ 12.90$ & - & - & $\$ 11.00$ \\
\hline Fi a $\$ 13$ & & & & $\$ 10.5$ \\
\hline
\end{tabular}

Fuente: Información recolectada directamente en los supermercados, junio de 2017. En los renglones señalados la fuente es el INCO, en su página de "Quién es Quién en los Precios".

sistemas e información y manejo de datos, etc., y finalmente, la reinversión en capacidad productiva e innovación tecnológica.

Estrategia de localización. Las estrategias de localización de las empresas harineras se han guiado por dos criterios: 1 . ubicarse en las zonas agrícolas productoras de maíz: la zona centro y occidental del país; $y, 2$. por la cercanía a los mercados más grandes dinámicos, como es el caso de aquellas plantas ubicadas en: el Estado de México, en la región Centro y Occidente, zonas donde se encuentran más de la mitad de las harineras, con las que cuenta el país, (33 de 63 plantas, ver Cuadro 2 anexo estadístico).

Capacidad instalada barreras a la entrada. El crecimiento de Gruma ha resultado en grandes escalas de producción que tienen la función de barreras a la entrada. El mercado de la harina se ha concentrado en: (1) la líder Gruma $^{8}$ cuenta en total con una capacidad instalada de 3 millones de toneladas, (2) Minsa con 878 mil toneladas, (3) Harimasa con solo 80 mil toneladas, y finalmente está Cargill que no reporta capacidad instalada en Mé-

8 Una de las últimas adquisiciones en el mercado nacional en 2005, fue Agroinsa. xico, posiblemente su producto es importado de sus plantas en el extranjero. (véase cuadro 3 en apéndice)

Esta gran capacidad de producción instalada, (resultado de sus enormes inversiones) opera como barreras a la entrada, y al considerar la economías de tamańo que supone, es una forma de competir y de excluir o desalentar a nuevos entrantes, $y$ en ese mismo sentido es que operan las otras marcas que dominan en el mercado. El mercado en México está distribuido de la siguiente forma: Gruma S.A.B. de C.V. la cual opera través de su subsidiaria Maseca S.A de C.V (con más del 70\%), y Minsa S. A. B. de C. V. (con más del 23\%), le siguen pero con menor importancia: Harimasa, S.A. de C.V.; Cargill de México, Molinos Anáhuac, y Productos Manuel José. (Ver cuadro 3 de apéndice)

Las enormes barreras a la entrada ${ }^{9}$ que posee Gruma es uno de los factores de poder que le permiten fijar un precio por encima del

9 Definimos una entrada a un mercado como el establecimiento de una nueva empresa que construye o incorpora nueva capacidad instalada productiva (J. Bain), además incluimos la idea de A. Koutsoyiannis 
competitivo, es decir igual o muy superior al costo medio de largo plazo, como lo ha argumentado J. S. Bain en otras investigaciones.

Las barreras a la entrada en el caso de Gruma y el mercado de harina de maíz toman las siguientes formas: 1) El exceso de capacidad instalada para la producción, las que además de ser una amenaza para los posibles entrantes, también se traduce en economías de escala ${ }^{10}$ que resultan de los diferentes eslabones de la cadena de valor; 2) Barreras de diferenciación de producto, si bien la harina de maíz es un producto homogéneo, la empresa ha logrado sembrar en la mente de los consumidores sus marcas; ${ }^{11}$ 3) Dado que es una empresa integra-

(1985, p 290) sobre considerar también la entrada de empresas ya existentes en otros mercados lo que define como entrada cruzada. Sin embargo, no consideramos en esta parte la adquisición de una empresa por otra mediante las compra de paquetes accionarios.

10 Se dividen en economías reales, aquellas que reducen los insumos de factores por unidad de producción. A su vez estas pueden ser del tipo: Técnicas. Resultado de un uso más eficiente de la maquinaria. Gerenciales. Resultado de una administración más eficiente. Podríamos ligar este concepto con las economías de conocimiento de E. Penrose. Y de mano de obra. Resultado de una mayor especialización de la misma. Y economías pecuniarias. Son las que reducen los precios de los insumos que la empresa compra. Se obtienen a partir de la compra de grandes cantidades a precios preferenciales, lo que reduce también los costos de transporte de dichos insumos.A. Koutsoyiannis (1985, p 295).

11 "La diferenciación del producto otorga a la empresa un cierto grado de control sobre el precio del artículo que fabrica, y es además, lo que motiva la publicidad y otras actividades de venta, que en el fondo tienen por objeto realizar las diferencias entre el articulo de una empresa y los rivales. Tales gastos afectan, a todas luces, tanto la demanda como los costos de la firma. Por añadidura, la diferenciación de los productos da origen a modificaciones internas de tipo organizativo de la empresa; así por ejemplo, las grandes firmas deben crear departamentos especiales de venta para organizar la promoción y distribución de sus artículos. Por último la diferenciación de los productos tiene también cierto influjo en la concentración de las

\section{as marcas son una forma de barreras a la entrada, con las cuales las empre- sas a través de la publicidad y la mercadotecnia han logra- do que los consumidores se identifiquen con ellas}

da verticalmente posee ventajas tecnológicas que se traducen en costos medios altamente competitivos, esto significa que tiene ventajas en costos; ${ }^{12}$ y 4) Los grandes capitales requeri-

empresas y en la estructura de las industrias."A. Koutsoyiannis (1985, p 292)“Bain descubrió que este tipo de barrera es la que más afecta la entrada"La magnitud de esta barrera está determinada por: 1. El monto de los gastos en publicidad y otros gastos requeridos para hacerse de un buen nombre. 2. La durabilidad y complejidad de los productos. 3. Método de distribución de la mercancía. A. Koutsoyiannis (1985, p 192).

12 Las barreras de costos se pueden visualizar en:

- La idoneidad del personal administrativo experto, con el que cuenta una empresa ya establecida.

- Patentes y conocimientos técnicos superiores (know-how).

- El control de las oferta de materias primas esenciales, en este caso la empresa "nueva" debe pagar un precio mayor por dichas materias primas o en su defecto utilizar sustitutos de menos calidad o más caros para su producción.

- Acuerdos establecidos con los proveedores o compras a gran escala de materias primas que disminuyen los precios para las grandes empresas ya establecidas en el mercado.

- Menores costos de capital para las empresas ya establecidas.

- Los menores costos de las empresas ya establecidas por la integración vertical de su producción.

- De acuerdo con Koutsoyannis, este tipo de barrera pierde fuerza si la "nueva" empresa que quieren ingresar a un mercado pertenecen a la misma industria (entrada desde adentro) o si proviene de otra industria (entrada cruzada). Ya que estas 
Gustavo Vargas Sánchez | El mercado de harina de maíz en México.

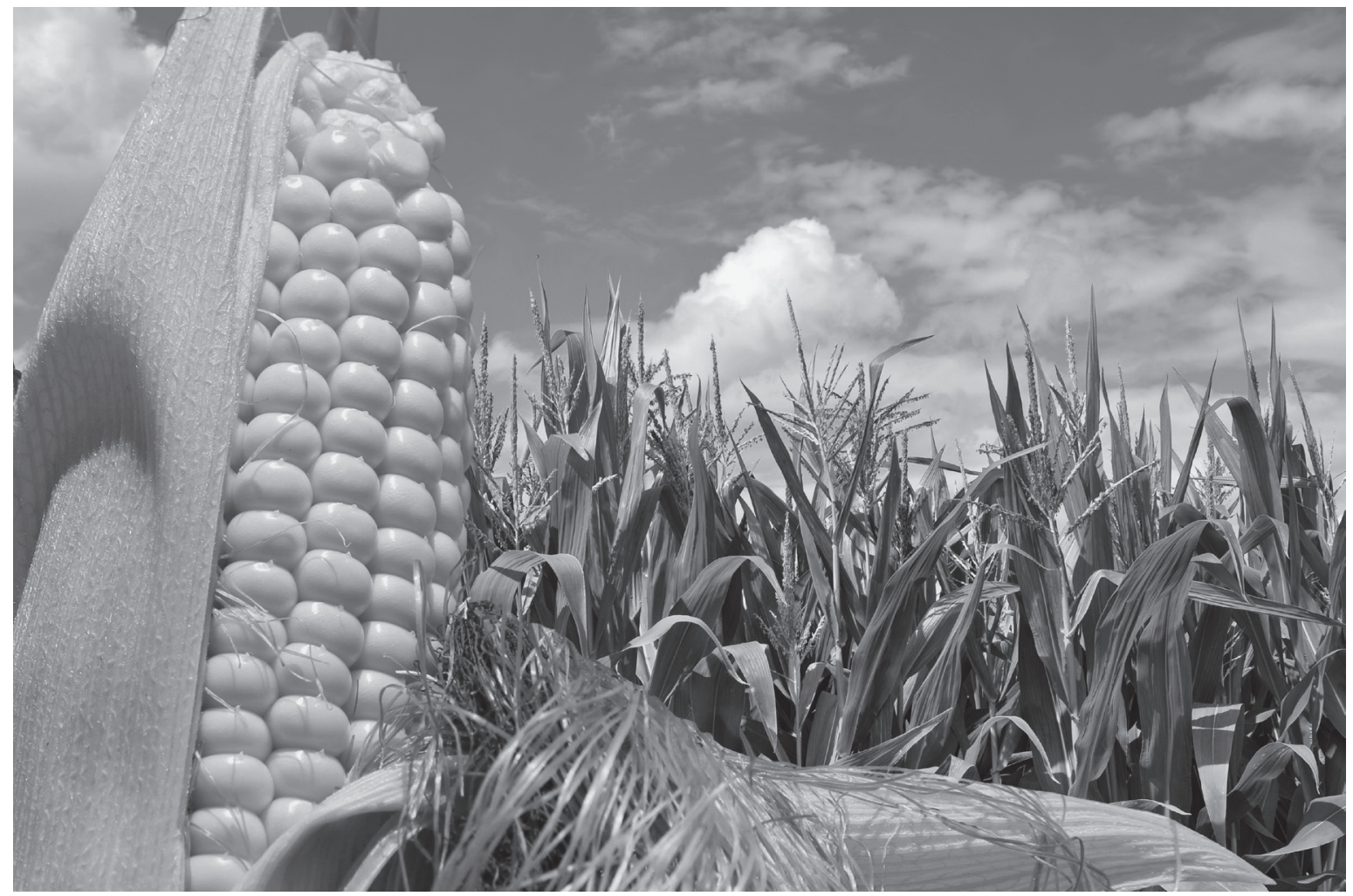

dos para ingresar y operar competitivamente en el mercado nacional. Finalmente, las marcas son una forma de barreras a la entrada, con las cuales las empresas a través de la publicidad y la mercadotecnia han logrado que los consumidores se identifiquen con ellas, en el caso de Gruma, sus marcas más conocidas son: Maseca, Mission y Guerrero. Aunque como resultado de sus estrategias de inversión en el extranjero han absorbido importantes empresas locales, las cuales cuentan con marcas propias, con las cuales se identifican los consumidores,

empresa ya cuentan con toda una infraestructura capaz de competir con las empresas ya establecidas en condiciones muy similares en términos de financiamiento, organización, abastecimiento de materias primas, administración e integración vertical. A. Koutsoyiannis (1985, p 294) Esta barrera a la entrada tambiíen pierde fuerza si una empresa ingresa a un mercado nuevo a través de la fusión $u$ adquisición de otra empresa que opera previamente en el mercado a disputar. y que la compañía ha sabido conservar para mantener su presencia en la mente de los compradores.

En la gráfica (2) siguiente presentamos una figura de la representación microeconómica del mercado de la harina de maíz y la oferta potencial. Gruma en México posee una capacidad instalada de 3,020 miles de toneladas, en tanto Minsa de solo 878. En el eje vertical colocamos los precios y los costos medios, consideramos que por las economías de tamaño y de tipo tecnología los costos medios de Gruma $\left(\mathrm{CMe}_{\mathrm{G}}\right)$ son menores a los costos medios de Minsa $\left(\mathrm{CMe}_{\mathrm{M}}\right)$. Esto se expresa, además en que los precios de Minsa son inferiores a los de Gruma. Finalmente podemos considerar, que los costos medios van decreciendo conforme se aumenta la producción y se llega al límite de la capacidad instalada. Esto se muestra en las curvas de costos medios de las dos empresas. 


\section{Gráfica 2 La oferta potencial y precios}

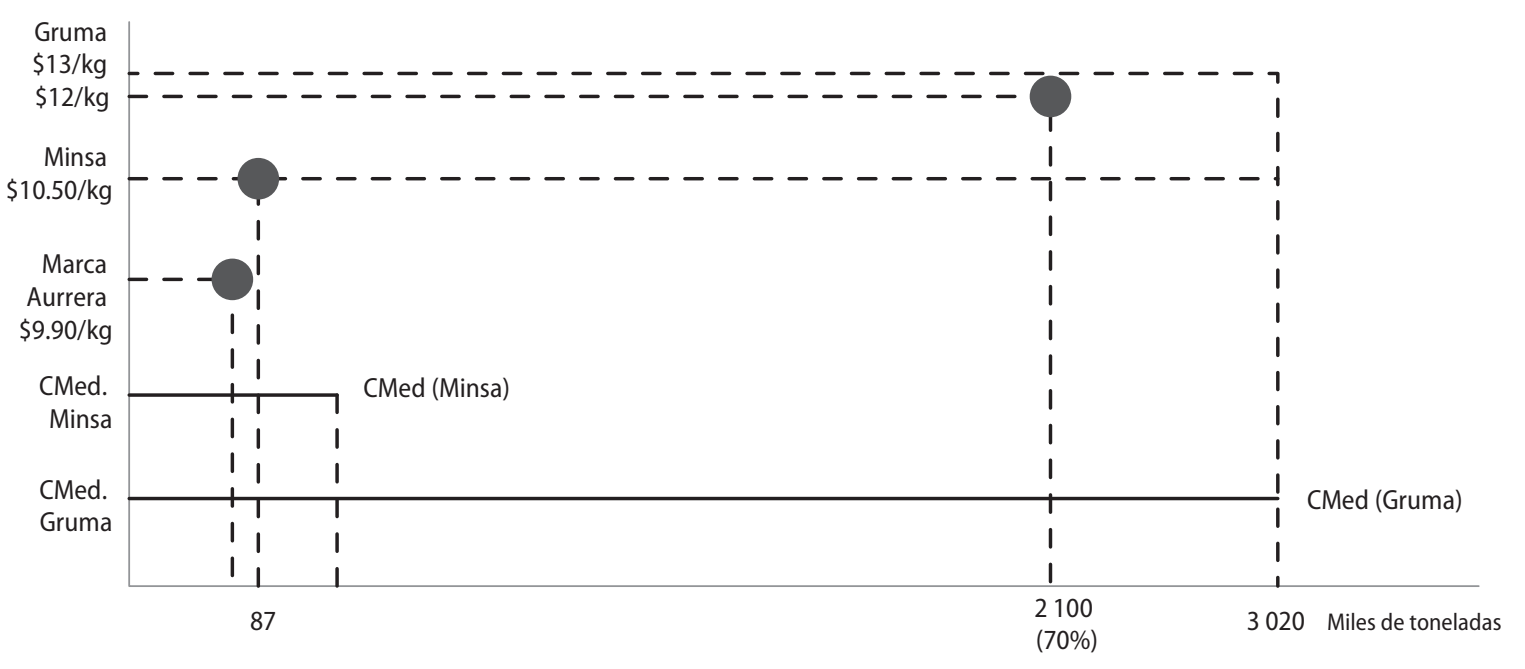

La diversificación en productos: esta ha sido una estrategia seguida por la compañía por lo cual cuenta con un amplio portafolio de productos entre los que destaca: harina, tortillas (diferentes presentaciones), y recientemente de forma destacable panes planos y sobre todo Wraps. Diversificación en mercados: Estados Unidos, América Latina, Europa, Asia y Oceanía. Recientemente la diversificación ha tocado al mismo negocio de Gruma en dos momentos, al transformarse en productora de wraps y en productora de alimentos balanceados para animales de granja.

Tamaño y poder de mercado. En el oligopolio una de las formas mas importantes de competencia está en función del poder de la empresa líder para determinar las reglas del juego, por ejemplo: 1. La fijación de precios y márgenes de utilidad. 2. Poder de fijar el precio de sus insumos estratégicos, y del precio de sus productos con empresas comercializadoras, oligopolios, mayoristas y venta al menudeo. 3. Capacidad instalada y capacidad no utilizada, como una amenaza y barreras de entrada a posibles entrantes. 4. Construcción de "lealtades" hacia una marca. 5. Influencia y capacidad de relacionarse y efectuar negociaciones con instituciones públicas y el gobierno. Gruma ha desarrollado todas formas de competencia.

\section{Precios y estrategia de fijación de precios de la Líder}

Algunas de las características más notables de los precios en el largo plazo son las siguientes: En primer lugar, una de las tendencia más notables de los precios nacionales (en dólares) de la harina de maíz, es que, luego del ajuste que sufrieron en 1997 y 1998, se han mantenido relativamente estables, fluctuando entre 500 y 600 dólares por tonelada. En segundo lugar, los precios internacionales se han venido incrementando desde hace treinta años, $y$ sobre todo a partir de la crisis internacional en 2007 y 2008. En tercer lugar, como resultado de las dos anteriores los precios nacionales e internacionales tienden a converger. Una cuarta característica es que los precios fijados por las empresas harineras en el mercado nacional están por encima de los que se observan en el mercado mundial pero tienden a igualarse. (Véase la gráfica 3). 
Gustavo Vargas Sánchez | El mercado de harina de maiz en México.

Es sobresaliente la tendencia a la convergencia entre los precios nacionales e internacionales, se pueden ubicar dos periodos: el primero que va de 1994 hasta la crisis del 2008 que se caracteriza por que la brecha entre esos precios se reduce hasta un nivel mínimo en 2009, el segundo periodo a partir de 2009 en que este sobreprecio continúa presente pero con una ventaja a favor de los precios internos, por lo que sigue resultado más rentable para las harineras comprar en el mercado nacional. Esta evolución puede explicarse entre otros factores por la entrada en vigor del TLC y salarios bajos.

En principio, los precios nacionales de harina de maíz deberían ser menores a los internacionales por la diferencia de costos, sobre todo en lo que toca a los salarios, sín embargo, como se puede apreciar en la gráfica 3, los precios de la harina de maíz siguen a los internacionales.

La evolución mencionada de los precios revela la situación oligopólica en el mercado de harina de maíz en México: las empresas lí- deres Gruma y Minsa poseen gran poder de fijación de precios en el mercado nacional, lo cual les permite tener un sobreprecio, esto es una ganancia extraordinaria de las empresas harineras en sus actividades en México con relación al precio que ellas mismas fijan en el mercado internacional. Esto trasluce prácticas de monopolio, y es más cuestionable considerando que los precios y los costos que existen en el mercado nacional son inferiores a los que tienen que pagar en el mercado internacional, en todo caso lo que podría haberse esperado era encontrar precios nacionales inferiores a los internacionales. En términos financieros, este margen de ganancia actúa como un flujo de financiamiento extraordinario para la expansión del oligopolio líder a nivel internacional.

\section{Costos, y beneficios}

Con objeto de tener un acercamiento al poder de mercado en la cadena de valor del maízharina- tortillas, y su capacidad de fijación de precios, a continuación vamos a realizar un

Gráfica 3 Precios de la harina de maíz (Dólares por tonelada)

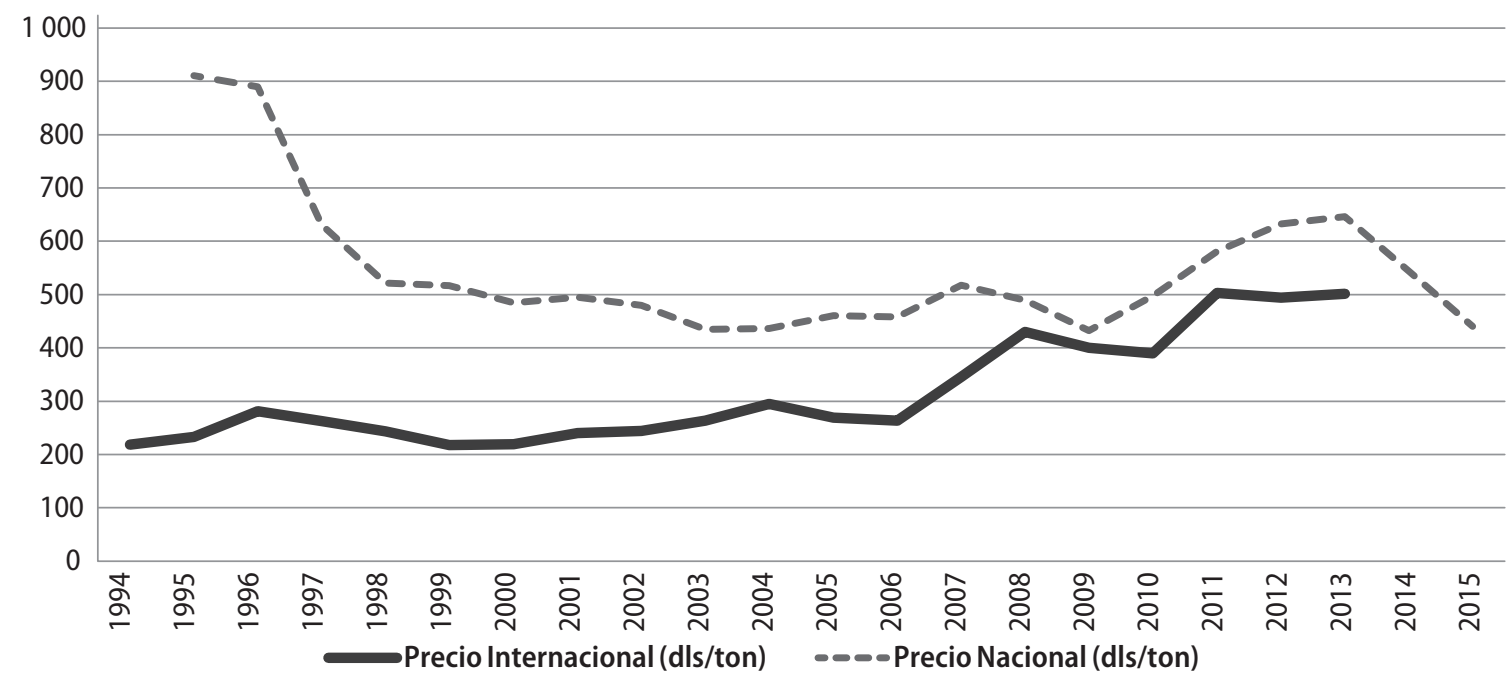

Fuente: Elaboración propia con base en datos de la FAO, de Banxico y del INEGI. 
ejercicio en la que transformamos las variables relevantes de costos en índices con objeto de hacer una comparación de largo plazo de la evolución de los costos básicos para la fabricación de la harina de maíz y deducir cualitativamente como ha aumentado el margen de ganancias de las empresas harineras: ${ }^{13}$

Precios del maiz. El maíz es la materia prima básica de la harina de maíz, por lo que su precio debería estar estrechamente correlacionado con el precio de ese producto. Como se muestra en la gráfica 4, el precio del maíz tanto nacional (como internacional) reporta una tendencia decreciente de 1961 a 2013 (aunque en el caso internacional las oscilaciones son mucho más pronunciadas y reporta un incremento a finales de los años dos mil). ${ }^{14}$ Lo cual indicaría una caída sostenida del costo del principal insumo (el maíz) para la elaboración de la harina de maíz, sin embargo, este reducción en los costos no se tradujo completamente en el precio de la harina, aunque su tendencia creciente se detuvo.

El comportamiento del precio internacional de la harina de maíz tiene un fuerte componente de costos, sobre todo el relacionado con el precio internacional del maíz por lo que ambos tienen un comportamiento muy semejante, se podría decir que el precio de la harina en el mercado internacional, a juzgar por sus costos tiene un comportamiento "normal". Lo importante es que los ciclos del precio de la ha-

13 En este ejercicio, en primer lugar, tomamos el precio de la harina de maíz a nivel nacional e internacional, por el lado de los costos; el precio del maíz nacional e internacional, el salario mínimo general, y el precio de la tortilla, en segundo lugar, todas las variables se transformaron a índices con base 2010, esto con objeto de poder comparar sus tendencia en el largo plazo, esto nos permite analizar la evolución de cada uno de ellos y la relación general precio-costo.

14 A partir de la apertura comercial de México en los noventas, las importaciones de Maíz en México se incrementaron de manera importante. rina a nivel internacional siguen el comportamiento de los precios internacionales del maíz. Una observación adicional es que los ciclos del precio internacional del maíz tienen efecto en las importaciones, la cuales dado su precio se han utilizado para sustituir la producción nacional.

El precio nacional del maíz, ha experimentado una reducción sostenida en el largo plazo, lo cual ha implicado un ahorro sustancial en los costos relativos de las empresas harineras locales. Se puede agregar que la reducción en los precios internacionales del maíz, y la liberalización de las importaciones, han abierto la posibilidad, para las empresas, de elegir comprar en el mercado interno o en el extranjero. El criterio de minimización de costos es el que está determinando donde comprar. Lo que deseamos subrayar en este ejercicio es que esta tendencia en los precios del maíz no corresponde a la tendencia observada en los precios de la harina de maíz ni de la tortilla, los cuales han ido en aumento en el mercado nacional, durante este periodo de estudio.

\section{I precio nacional del maíz, ha experimen- tado una reducción sostenida en el largo pla- zo, lo cual ha implicado un ahorro sustancial en los costos relativos de las em- presas harineras locales}


Gustavo Vargas Sánchez | El mercado de harina de maiz en México.

Una interpretación microeconómica

Gráfica 4 Índice 2010 para el precio de la tortilla, maíz, harina y el salario mínimo general

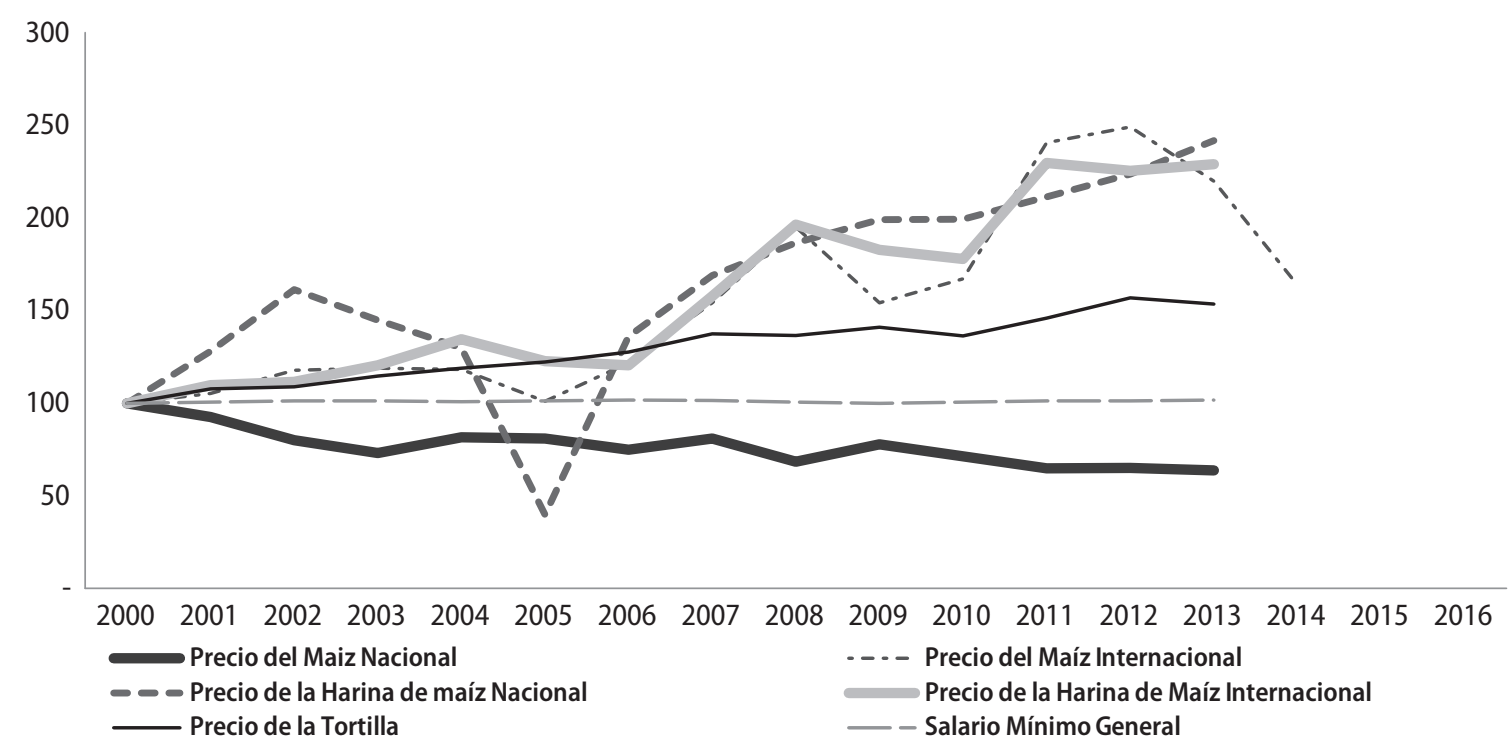

Fuente: elaboración propia a partir de los datos que publica la FAO, el Sistema Nacional de Información e Integración de Mercados (SNIIM) y el Centro de Estudios de las Finanzas Públicas de la Cámara de Diputados, los precios de las tortillas a partir del 2010 fueron tomados de Retes Mantilla, Rogel Fernando, Dr. (2010), Demanda de la totilla de maíz en México, 1996_2008, Tesis, Colegio de Postgraduados, Campus Montecillo, p 26.

Sueldos y Salarios. Estos son una parte sustancial de los costos de la elaboración de harina, también presentan dos periodos: en general estos se han mantenido estancados, y se presentan como una línea casi horizontal, sin embargo se puede notar una tendencia hacia la baja que va desde la devaluación de 1982, y hasta 1999, como se puede observar en la gráfica 4. A partir del 2000, el salario real se recuperó lentamente hasta 2007, pero no logró el nivel que tenía en los noventa. Después de 2009 el salario mínimo real se ha recuperado. ${ }^{15}$

Dado que los dos principales costos de producción de la harina de maíz no han aumentado (maíz con tendencia a la baja y el salario estable) y el desarrollo positivo de la tecnología (creciendo la productividad del trabajo y del capital en la producción de harina), ¿por qué

15 Esta tendencia en 2017 claramente se ha revertido, sin embargo, dado el periodo del ejercicio de comparación no introducimos esta información. los precios de la harina de maíz, desde 1998 se han mantenido estables, y en los últimos años han aumentado (excepto 2014 y 2015)? En otras palabras, ¿qué explica la brecha creciente entre el precio nacional de la harina de maíz y sus principales costos?

La respuesta a esta pregunta está por una parte, en el poder de mercado de las grandes productoras nacionales de harina, que influyen en el precio de las tortillas. Esto contrasta con el débil poder de negociación de los trabajadores para aumentar sus salarios. Por otra parte, en la misma dirección también ha jugado la política macroeconómica (de subsidios) que ha buscado la estabilidad de precios, entre otros medios a través de controlar los productos básicos (maíz) y el salario mínimo general (ver gráfica 4), al mismo tiempo de la política de liberalización del precio de la tortilla, y por supuesto de la harina. 
En resumen, el margen de ganancia de las empresas harineras se ha incrementado, lo cual se explica en primer lugar por que existe una brecha creciente entre el precio nacional de la harina de maíz y el precio del maíz, en segundo lugar los sueldos y salarios se mantienen estables en el periodo de estudio. Esto se puede ver claramente en la gráfica 4, en la cual la brecha entre esas variables se ha incrementado desde el año 2000. En segundo lugar, porque el precio de la harina de maíz en México se ha indexado al precio internacional (el cual se comporta en la misma dirección que el precio del maíz en el mercado mundial). Esta puede ser la argumentación de por qué los precios nacionales de la harina de maíz se han incrementado, aunque no se justifica, pues los costos relevantes son el precio del maíz en el mercado nacional y, los sueldos y salarios en México. Los beneficiados de esta dinámica de largo plazo han sido sin duda las empresas harineras, y en menor medida los fabricantes de tortillas.

\section{Estrategia de fijación de precios de la líder}

En términos reales $(100=2003)$ el precio de la harina de maíz se ha ido incrementando, pasó de cuatro mil pesos en 2000 hasta más de siete mil en 2012. Esto muestra la posición privilegiada de la empresa en la captación nacional de valor, que, por otra parte contrasta con el poder de compra de los salarios los cuales se han mantenido estancados. Por supuesto esto se explica por el poder de fijación de precios de la compañía.

La estrategia de Gruma en la fijación de sus precios posee las siguientes características: 1. De forma sistemática el incrementos de sus precios son superiores a la tasa de inflación nacional, por lo cual su línea de precios reales es creciente, por tanto, no existe deterioro en el poder monetario de sus ingresos. 2. Fija perió- dicamente lo que podemos llamar un precio de reserva inflacionario, (ver gráfica 5) que consiste en que no solo se protege de la inflación sino que fija un precio (y una tasa de crecimiento de los mismos) suficientemente grande como para soportar la inflación en los años siguientes. Este es el caso de 2003, 2007 y 2011, y es seguramente lo que ha ocurrido a inicios de 2017. La fijación de esta tasa de reserva es cíclica y le permite en los años siguientes hacer "ligeros" ajustes para protegerse de la inflación reportada cada año. Sin embargo el ciclo que sigue no es fijo sino se ajusta según la misma inflación y las expectativas que sobre esta variable tenga la compañía. En promedio durante el periodo analizado, los precios de Gruma han crecido un $5 \%$ (promedio simple), por encima del promedio del Índice Nacional de Precios al Consumidor (INPC o inflación) el cual ha sido de 4.08\%. (Ver gráfica 5)

Las fluctuaciones de los precios de la harina de maíz y de la tortilla no afectan la demanda, la cual es rígida al precio, esta característica, más el poder de fijación de precios, han resultado en importantes flujos de efectivo para Gruma, los cuales han podido ser utilizados para sanear sus finanzas, al mismo tiempo que obtener recursos para financiar sus proyectos de expansión internacional.

En resumen, el mercado de la harina en México es de carácter oligopólico. Por un lado, la oferta está conformada por: Gruma, MinsaBunge y Cargill, y una empresa local Harimasa. Gruma es la empresa líder en el mercado, es una empresa nacional de carácter multinacional. Minsa a partir de 2016 es propiedad mayoritaria de Bunge, ésta es una enorme empresa multinacional (ver apéndice al final del libro), y Cargill también es una poderos corporación multinacional que tiene una participación marginal en el mercado local. Por el lado de la demanda, se forma por: 1. Las mi- 
Gustavo Vargas Sánchez | El mercado de harina de maiz en México.

Una interpretación microeconómica

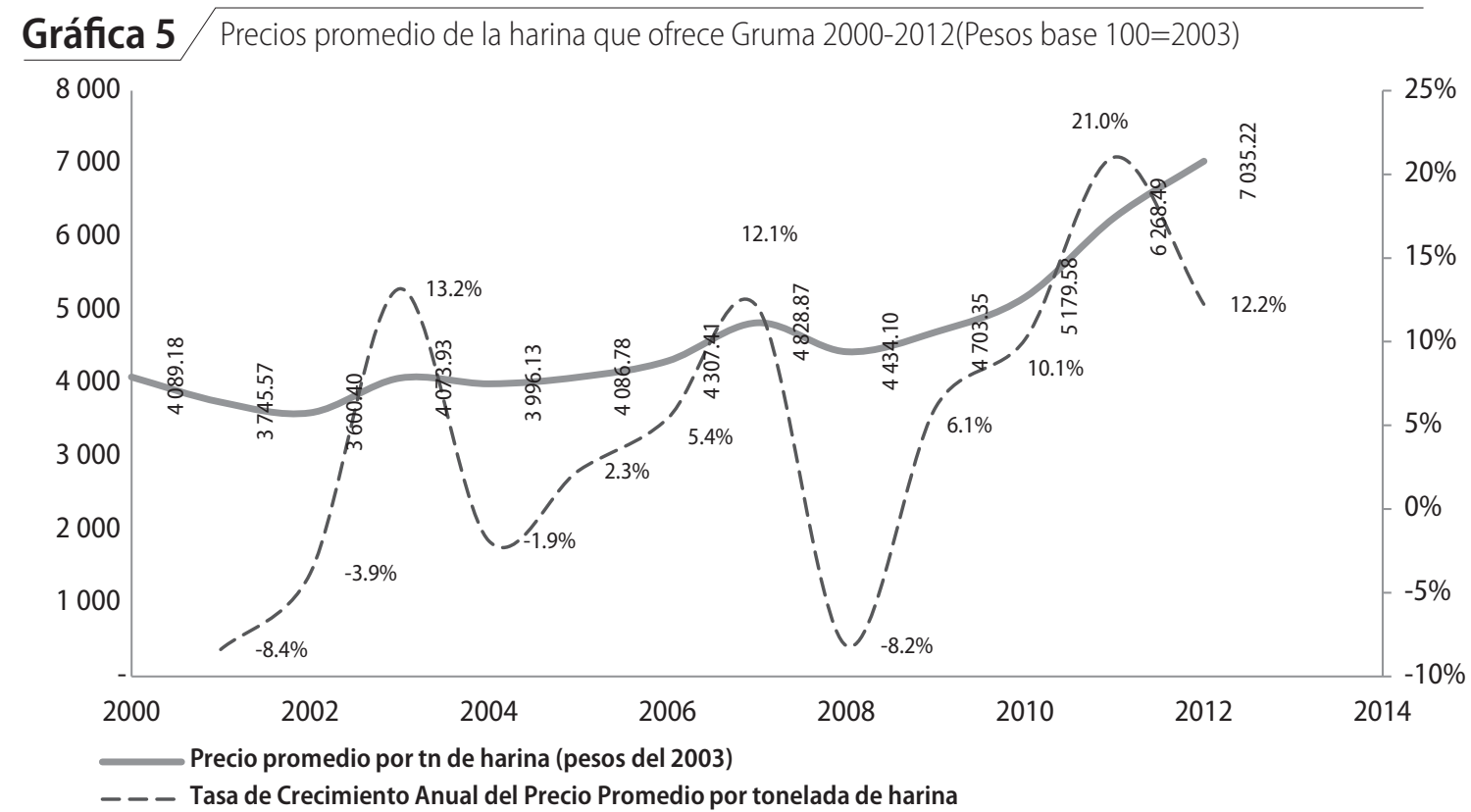

Fuente: elaboración propia, los precios por tonelada de harina es una estimación propia sobre los volúmenes de ventas de Gruma y el valor de las ventas de la empresa de 2001 al 2013, datos que se obtuvieron de los reportes anuales de Gruma a la BMV.

les de microempresas o tortillerías que venden a los millones de consumidores nacionales, 2 . Unas pocas micro empresas que producen tortillas empaquetadas y productos sustitutos, 3 . Intermediarios formados por $a$. supermercados: Walmart, Soriana, Comercial Mexicana, Chedraui, $b$. Algunas cadenas de minoristas: Oxxo, Seven, etc., otros intermediarios. Y al final de la cadena están los millones de consumidores se comportan como tomadores de precios.

Las corporaciones multinacionales con Gruma como líder en el mercado nacional determinan los precios. El precio al que compran los intermediarios depende de su tamaño, quienes están un una mejor posición de negociación son las cadenas de supermercados, y de minoristas, las tortillerías agrupadas en asociaciones también pueden tener algunos descuentos por volumen. Al final de la cadena los millones de consumidores finales, tanto de harina como de tortillas aparecen como precio aceptantes. En la formación de precios la estructura anterior determina el poder para fijar precios o de negociar los mismos, algo que no tienen los demandantes finales. El cuadro 2, resume la estructura del mercado de la harina.

Representación microeconómica de la fijación de precios de Gruma

En esta estructura oligopólica de mercado del mercado de harina de maíz tenemos la siguiente información: la oferta está constituida por un duopolio, donde existe una corporación líder que fija precios, y otra que se comporta como seguidora pero con precios diferentes (menores), su capacidad instalada y sus costos medios se presentan (figura 1). Si bien los productos son casi sustitutos perfectos, no existe un solo precio y el mercado no se vacía a favor del precio menor. Las curvas de costos medios totales son descendentes hasta llegar al máximo de su capacidad instalada. La empresa ope- 
Cuadro 2. Mercado de harina de Maíz en México

\begin{tabular}{cc}
\hline Oferta & Demanda \\
\hline 1. Gruma & \\
2. Minsa-Bunge & Millones de consumidores \\
3. Cargill & \\
4. Harimasa & Precio-aceptantes \\
\hline Fijadoras de precios &
\end{tabular}

ra al $70 \%$ de dicha capacidad . Dado que el nivel de producción de las dos seguidoras son mucho menores a la líder, asumimos que sus costos medios son mayores. La representación de la capacidad instalada, utilizada y los costos medios para las dos plantas se pueden ver en la gráfica 2, ahora con objeto de analizar la fijación de precios de Gruma solo consideramos los datos para esta empresa, y representamos su curva de costos medios descendente como se ve en la gráfica 6 .

En cuanto a los precios, dado que en promedio Gruma opera a 70\% de su capacidad instalada, y el conocimiento sobre el comportamiento de la demanda, la compañía fija un precio a partir de sus costos medios a un $70 \%$, más un margen de ganancia que ha de considerar la competencia de sus dos rivales, y sus expectativas. Esos precios no varían con los cambios instantáneos de la demanda sino que los mantiene estables durante varios meses. Los precios fijados con este método forman una curva horizontal, que no es otra cosa que la curva de oferta de corto plazo. En resumen, la curva de oferta es horizontal al nivel de los precios fijados en el corto plazo. Dado el exceso de capacidad instalada, este precio se sostiene hasta que la empresa decide cambiarlo según los criterios mencionados y su percepción de la marcha del mercado.

\section{Gráfica 6} Representación micro de la fijación de precios de Gruma

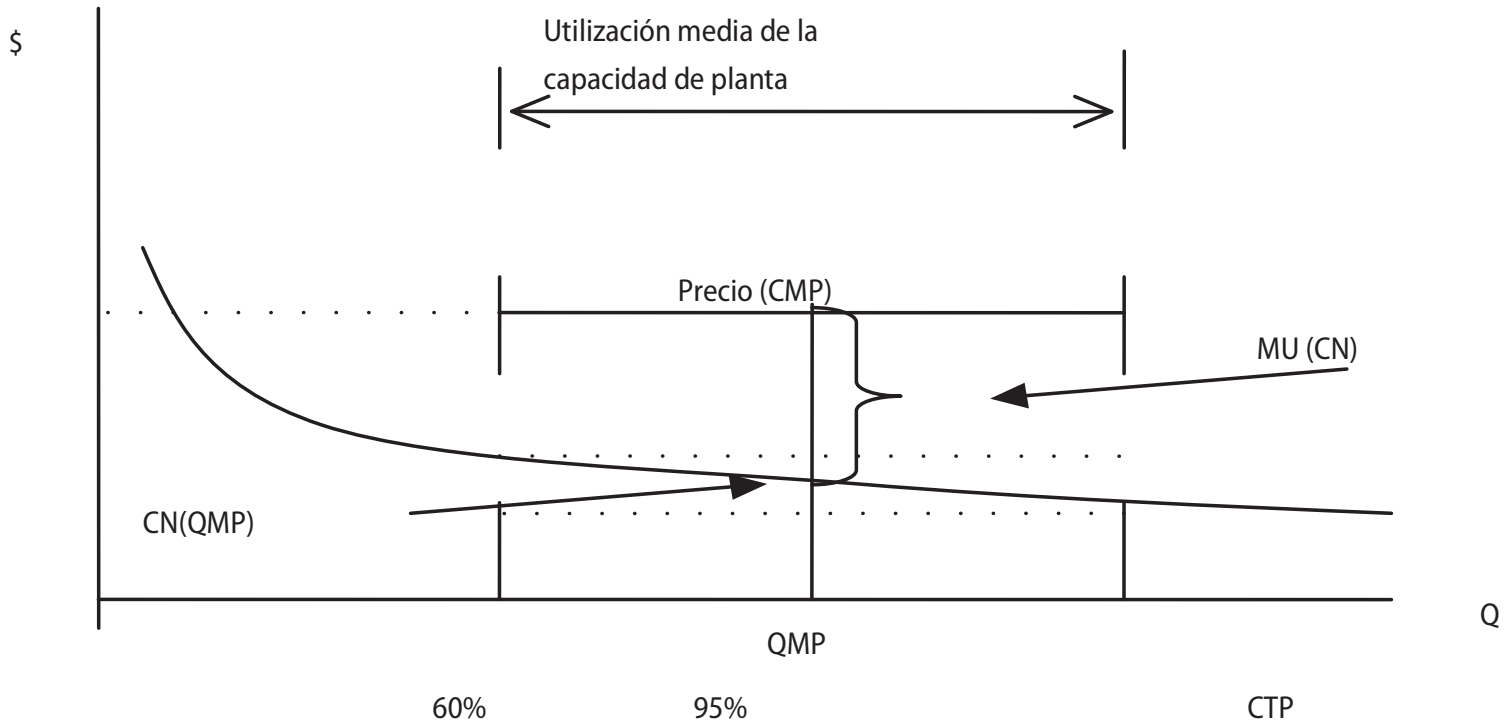


Gustavo Vargas Sánchez | El mercado de harina de maíz en México.

Por el lado de la demanda, ¿cómo representar en un gráfico la curva de la demanda?, si sabemos que, la demanda es rígida ante los cambios en los precios, el consumo agregado está estancado o crece muy lentamente, el consumo per cápita está estancado y se reduce, la demanda se explica por las necesidades, el ingreso y la cultura. Las empresas menores fijan precios sus precios por debajo de los precios de la empresa líder, y la demanda no responde como se dice en los libros de texto dirigiéndose a los oferentes con precios menores. Si la demanda no cambia con los precios, no parece adecuado representarla con un línea ni negativa ni positiva, lo más conveniente es colocarla como un punto, a lo largo de la curva de la oferta. En resumen esta estructura de oferta y demanda del mercado se presenta en la gráfica 6 .

La figura anterior representa microeconómicamente la comportamiento de la oferta y la demanda en el caso de estudio, y cómo la empresa fija sus precios. La línea de precios de corto plazo, es el precio fijado y que supone la utilización media de la capacidad instalada (CMP), representa la curva de la oferta. El costo medio o normal calculado (CN (QMP)) correspondiente a cantidad media de producción (QMP), que en este caso es de 70\% de la capacidad instalada, a ese nivel corresponde un punto en la curva de costos medios totales. A este costo se agrega un margen de utilidades o de operación $(\mathrm{MU}(\mathrm{CN}))$ y se obtiene el precio de mercado el cual es vigente en el corto plazo.

La demanda del mercado se puede ubicar como un punto a lo largo de la curva de oferta (precio), por ejemplo, podemos suponer que está precisamente en la intersección de QMP y el precio. En la práctica la demanda efectiva de harina puede aumentar o disminuir, lo relevante es que habiéndose fijado el precio, cambios en la demanda se pueden representar como desplazamientos hacia la izquierda o hacia la derecha, pero estos cambios no alteran el precio de la harina.

Finalmente, los movimientos de la demanda a lo largo de la curva de oferta dan lugar, no cambios en los precios, sino a la utilización de la capacidad productiva y al empleo. Por ejemplo, un fenómeno bien estudiado por la empresa, es lo que ocurre en los días de fiestas patrias, en los cuales la demanda de harina de maíz aumentan considerablemente, lo cual se prevé aumentando la demanda de maíz, mayor ocupación en sus plantas, más volúmenes de comercialización. Por ejemplo la forma como representamos lo anterior sería, desplazar la el punto de intersección señalado "A" a la derecha por ejemplo hasta, por ejemplo, el punto "B" con una utilización del $95 \%$ de la capacidad lo que se acompañaría de un crecimiento en el empleo de mano de obra y del resto de los recursos productivos. Variaciones en la demanda efectiva de corto plazo no da lugar a cambios en el precio sino en el empleo.

\section{Conclusiones}

El mercado interno de la harina de maíz posee las siguientes características: 1 . crece lentamente y tiende al estancamiento. 2. Es un mercado oligopólico dominado por dos empresas: Gruma y Minsa-Bunge. 3. Estas empresas tienen capacidad de fijar precios, y la forma de competencia transciende la competencia de precios, toma formas estratégicas. 4. La demanda está diluida en millones de consumidores que se comportan como precio aceptantes y su demanda está determinada por sus necesidades, costumbres e ingreso principalmente. 5. El funcionamiento de este mercado es un espacio para el análisis microeconómico por lo que aquí elaboramos una aproximación teórica. 
La elasticidad de la demanda de harina de maíz es rígida. La demanda de harina de maíz al ser el insumo básico en la elaboración de las tortillas, alimento fundamental en la dieta de los mexicanos no depende del precio. La elasticidad precio de la demanda es cero, por lo cual podemos decir que la cantidad demandada es función de las necesidades, cultura e ingreso de los consumidores. La respuesta particular de los consumidores a los cambios en la demanda puede ser más compleja y estar asociada a los estratos socioeconómicos y en aquellos con ingresos menores se puede comportar como un bien Giffen. La característica de rigidez de la demanda confiere a los oligopolios un gran poder para determinar los precios pues saben que el aumentarlos no implicaría un reducción en sus ventas. Por lo que incrementos en los precios se convierte en una fuente adicional de financiamiento para sus planes de expansión. La teoría de Eichner ${ }^{16}$ que muestra la relación entre variación de precios y fuentes de financiamiento se revela sumamente importante para la comprensión del comportamiento micro de las corporaciones.

Formas de competencia son múltiples y variadas: Las formas de competencia cambian según el contexto de las empresas, su mercado y las características socio-políticas del país, en sus estrategias destacan:

- Las estrategias de inversión de Gruma en el mercado nacional que la han llevado a poseer una capacidad productiva que sobrepasa la misma demanda nacional, e implica una utilización del $70 \%$ en promedio.

- Localización y distribución geográfica de la oferta se caracteriza por: ubicarse cerca de los grandes mercados de consumidores, $y$, en segundo lugar, en el corazón de las zonas productoras de maíz.

16 Eichner, p. 376, 381, 382 y392,
- Las empresas harineras han construido importantes barreras en la forma de inversión, capacidad instalada, tecnología, mercadotecnia, un sofisticado sistema de comercialización, etc., las cuales son muy difíciles de igualar o superar. Aquí hemos puesto en evidencia dos tipos de barreras: la magnitud de la inversión requerida para competir, y la capacidad instalada de las empresas las cuales son substancialmente superiores a la demanda nacional, lo cual hace inviable (no rentable) grandes inversiones para competir contra el duopolio existente.

- El poder oligopólico de Gruma, le ha permitido fijar altos (y crecientes) márgenes de ganancia. Esta estrategia se ha visto favorecida al menos por: salarios bajos y estables, costos del maíz con una tendencia hacia la baja en términos relativos. El comportamiento de la empresa seguidora, parece haberse acomodado a la estrategia de la líder, por lo que la competencia a través de precios no existe.

- La competencia entre las empresas se presenta en espacios como: puntos de venta (supermercados), sistemas de comercialización, atención al cliente, publicidad y mercadotecnia. Esta forma de competir quita importancia a la diferencia de precios al consumidor. El cual se comporta como precio aceptante

El análisis microeconómico en el caso de Gruma, nos permite decir que el mercado de la harina es oligopólico concentrado. Por el lado de la oferta, Gruma se comporta como líder y fijadora de precios y las otras como seguidoras, acomodan sus precios.

La teoría del oligopolio actual enfrenta un reto analítico: supone que existe una curva de demanda dada y el reparto del mercado surge por ajustes entre los precios y las cantidades, la solución de esta dicotomía genera trayectorias que conducen finalmente a un punto optimo de precios-cantidades, y distribución 
Gustavo Vargas Sánchez | El mercado de harina de maíz en México.

del mercado entre los competidores, la interdependencia es función del proceso de ajuste entre aquellas dos variables. Las características del mercado nacional de la harina que estamos analizando no muestra que haya ajuste vía precios. La competencia es de no-precios.

La curva de la demanda no se puede suponer como dada y con una elasticidad determinada. Considerando que existen precios diferentes para la harina y con participaciones más o menos estables en el mercado, la demanda no es función del precio (o por la existencia de un segmento quebrado al estilo de la curva quebrada de Sweezy), en la estrategia de Gruma no se contempla, ni se ha considerado bajar los precios al nivel fijado por Minsa. Y por su parte ésta no ha aumentado los precios al nivel de la primera.

Una representación alternativa a los enfoques tradicionales del oligopolio, nos permite considerar que los determinantes de la oferta y la demanda son diferentes, y poseen su propia dinámica: la curva de la oferta está determinada por los costos medios y el poder de fijación de un margen de ganancia. La demanda es función de las necesidades, de los ingresos y la cultura de los mexicanos. La curva de oferta es horizontal, como lo sostienen las teoría heterodoxas, esto nos permite representar la demanda como un punto en la curva de la oferta. Con este sistema, podemos explicar como los movimientos de la demanda en el corto plaza determinar el empleo y la ocupación en la empresa y el mercado.

\section{Bibliografía}

Eichner, Alfred, S., The Megacorp and Oligopoly, Micro Fundations of Macro Dynamics, Cambridge University Press, Londres, Nueva York, Melbourne, 1976.

Koutsoyiannis, Anna. (1985). "Microeconomía moderna”. Amorrortu editores. Buenos Aires, Argen- tina.

Penrose, Edith Tilton. (1962). "La teoría del crecimiento de la empresa”. Edit. Aguilar S.A. de ediciones, España.

Porter, Michael. (1996). "Estrategia Competitiva. Técnicas para el análisis de los sectores industriales y de la competencia”. Edit. Compañía Editorial Continental, México.

Milling and Grain (2015) página web: http://grainfeedla.com/el-mercado-mundial-de-la-harina/

Cámara de Diputados (2016), Centro de Estudios de las Finanzas Públicas, "Series Históricas, Indicadores Macroeconómicos," información consultada el 24 de junio de 2016, en la página web: http://www3.diputados.gob.mx/ camara/001_diputados/006_centros_de_estudio/02_centro_de_estudios_de_finanzas_publicas__1/005_indicadores_y_estadisticas/01_historicas/01_ind_macroeconomicos_1980_2012

cDressa de la Cámara de Diputados (2014), "Evolución de los precios del maíz, frijol y sorgo," información consultada el 9 de agosto del 2016, en la página web: file://C:/Users/Invitado/Downloads/ Reporte_Precio_de_granos_30-10-2014.pdf

Centeno Juárez Mario, El Economista (22/07/2015), "Impulso a las actividades de la red maiz en México (I)" información consultada el 03 de agosto del 2016, en la página web: http://eleconomista.com. mx/columnas/agro-negocios/2015/07/22/impulsolas-actividades-red-maiz-mexico-i

Comisión de Desarrollo Social de la Cámara de Diputados LX Legislatura (2007), El Maíz en el Mundo y en México.

Pérez León Israel, (2010), Tesis, "El grupo Gruma uno de los principales conglomerados alimenticios en México: 1998-2007 y base constitutiva de la élite empresarial mexicana." Facultad de Economía.

Retes Mantilla, Rogel Fernando, Dr. Tesis, (2010), Demanda de la tortilla de maíz en México, 1996_2008, Colegio de Postgraduados, Campus Montecillo.

Тімотну A. Wise, (2008), "Estado de emergencia para el maíz mexicano: Proteger la agrobiodiversidad 


\section{ECONOMÍA INFORMA | 405 | JULIO-AgOSTO 2017 |}

apuntalando a la economía campesina" Publicado en Desde los Colores del Maíz: Una agenda para el campo mexicano, J. Luis Seefoó Luján, editor, El Colegio de Michoacán, página web: http://www. ase.tufts.edu/gdae/Pubs/rp/PolicySpaceMexicanMaizeSpanMay07.pdf

Moreno, Luis, Milenio (12/02/2015), “Importaran 30 mil mdp de maíz amarillo transgénico”, página web: http://www.milenio.com/negocios/importaran_maiz_transgenico-maiz_amarillo_transgenico_0_463153688.html

Servicio de información Agroalimentaria y Pesque- ra (SIAP, 2012), "Situación actual y perspectivas del Maíz en México 1996-2012”, información consultada en linea, página web: http://www. campomexicano.gob.mx/portal_siap/Integracion/ EstadisticaDerivada/ComercioExterior/Estudios/ Perspectivas/maiz96-12.pdf

FAO (2016), página web: http://faostat3.fao.org/ download/T/TP/S

INEGI (2016), página web: www.inegi.org.mx/

Banco Mundial (2016) página web: www.bancomundial.org/

\section{Anexo Estadístico}

Cuadro A1. Elasticidad precio de la demanda de harina de maíz

\begin{tabular}{|c|c|c|c|c|c|c|}
\hline Año & $\begin{array}{l}\text { Volumen de ven- } \\
\text { tas de harina de } \\
\text { maíz (toneladas) }\end{array}$ & $\begin{array}{c}\text { Valor de ventas de } \\
\text { harina de maíz (miles de } \\
\text { pesos corrientes) }\end{array}$ & $\begin{array}{l}\text { Precio (por } \\
\text { tonelada) }\end{array}$ & $\begin{array}{l}\text { Tasa de cambio } \\
\text { del volumen } \Delta \mathbf{Q}\end{array}$ & $\begin{array}{c}\text { Tasa de } \\
\text { cambio del } \\
\text { precio } \Delta \mathrm{P} \\
\end{array}$ & $\begin{array}{c}\text { Elasticidad } \\
\text { precio de la } \\
\text { demanda } \\
\end{array}$ \\
\hline 1994 & 1992122.0 & 2361157.0 & 1185.2 & & & \\
\hline 1995 & 2296242.0 & 3299523.0 & 1436.9 & 15.27 & 21.23 & 0.72 \\
\hline 1996 & 2614212.0 & 5596438.0 & 2140.8 & 13.85 & 48.98 & 0.28 \\
\hline 1997 & 2307925.0 & 4701239.0 & 2037.0 & -11.72 & -4.85 & 2.42 \\
\hline 1998 & 2299516.0 & 5344311.0 & 2324.1 & -0.36 & 14.09 & -0.03 \\
\hline 1999 & 1885601.0 & 5252748.0 & 2785.7 & -18.00 & 19.86 & -0.91 \\
\hline 2000 & 1781290.0 & 5048592.0 & 2834.2 & -5.53 & 1.74 & -3.18 \\
\hline 2001 & 1676501.0 & 5109372.0 & 3047.6 & -5.88 & 7.53 & -0.78 \\
\hline 2002 & 1605967.0 & 5156382.0 & 3210.8 & -4.21 & 5.35 & -0.79 \\
\hline 2003 & 1551107.0 & 5262452.0 & 3392.7 & -3.42 & 5.67 & -0.60 \\
\hline 2004 & 1566702.0 & 5848229.0 & 3732.8 & 1.01 & 10.03 & 0.10 \\
\hline 2005 & 1593991.0 & 6293720.0 & 3948.4 & 1.74 & 5.78 & 0.30 \\
\hline 2006 & 1663829.0 & 6780381.0 & 4075.2 & 4.38 & 3.21 & 1.36 \\
\hline 2007 & 1669650.0 & 7928454.0 & 4748.6 & 0.35 & 16.52 & 0.02 \\
\hline 2008 & 1715802.0 & 8310522.0 & 4843.5 & 2.76 & 2.00 & 1.38 \\
\hline 2009 & 2304135.0 & 12613156.0 & 5474.1 & 34.29 & 13.02 & 2.63 \\
\hline 2010 & 2272264.0 & 13937454.0 & 6133.7 & -1.38 & 12.05 & -0.11 \\
\hline 2011 & 2415579.0 & 17575512.0 & 7275.9 & 6.31 & 18.62 & 0.34 \\
\hline 2012 & 2376630.0 & 20771028.0 & 8739.7 & -1.61 & 20.12 & -0.08 \\
\hline 2013 & 2299818.0 & 20681620.0 & 8992.7 & -3.23 & 2.90 & -1.12 \\
\hline 2014 & 2329299.0 & 19122974.0 & 8209.8 & 1.28 & -8.71 & -0.15 \\
\hline 2015 & 2420675.0 & 19694010.0 & 8135.8 & 3.92 & -0.90 & -4.35 \\
\hline 2016 & 2502486.0 & 21567987.0 & 8618.6 & 3.38 & 5.94 & 0.57 \\
\hline Promedio & 2049623.6 & & 4666.3 & & & -0.09 \\
\hline Arco & & & & & & 0.16 \\
\hline
\end{tabular}

Fuente: Elaboración propia con base al CMAP y EMIN, INEGI. En su página http://www.inegi.org.mx a 07/06/2017. 
Gustavo Vargas Sánchez | El mercado de harina de maiz en México.

Una interpretación microeconómica

Cuadro A2. Elasticidad ingreso de la demanda de harina de maíz

\begin{tabular}{|c|c|c|c|c|c|}
\hline Año & $\begin{array}{l}\text { Volumen de ven- } \\
\text { tas de harina de } \\
\text { maíz (toneladas) }\end{array}$ & $\begin{array}{c}\text { Salario mínimo } \\
\text { general promedio } \\
\text { (pesos diarios) }\end{array}$ & $\begin{array}{l}\text { Tasa de cambio } \\
\text { del volumen } \Delta \mathbf{Q}\end{array}$ & $\begin{array}{c}\text { Tasa de cambio } \\
\text { del salario } \Delta I\end{array}$ & $\begin{array}{c}\text { Elasticidad ingreso } \\
\text { de la demanda }\end{array}$ \\
\hline 1994 & 1992122.0 & 13.73 & & & \\
\hline 1995 & 2296242.0 & 14.69 & 15.27 & 6.98 & 2.19 \\
\hline 1996 & 2614212.0 & 18.11 & 13.85 & 23.24 & 0.60 \\
\hline 1997 & 2307925.0 & 23.83 & -11.72 & 31.60 & -0.37 \\
\hline 1998 & 2299516.0 & 27.38 & -0.36 & 14.90 & -0.02 \\
\hline 1999 & 1885601.0 & 31.21 & -18.00 & 13.98 & -1.29 \\
\hline 2000 & 1781290.0 & 34.34 & -5.53 & 10.06 & -0.55 \\
\hline 2001 & 1676501.0 & 37.28 & -5.88 & 8.56 & -0.69 \\
\hline 2002 & 1605967.0 & 39.53 & -4.21 & 6.02 & -0.70 \\
\hline 2003 & 1551107.0 & 41.36 & -3.42 & 4.64 & -0.74 \\
\hline 2004 & 1566702.0 & 43.18 & 1.01 & 4.39 & 0.23 \\
\hline 2005 & 1593991.0 & 44.93 & 1.74 & 4.07 & 0.43 \\
\hline 2006 & 1663829.0 & 46.73 & 4.38 & 3.99 & 1.10 \\
\hline 2007 & 1669650.0 & 48.55 & 0.35 & 3.90 & 0.09 \\
\hline 2008 & 1715802.0 & 50.49 & 2.76 & 4.00 & 0.69 \\
\hline 2009 & 2304135.0 & 52.85 & 34.29 & 4.67 & 7.35 \\
\hline 2010 & 2272264.0 & 55.41 & -1.38 & 4.85 & -0.29 \\
\hline 2011 & 2415579.0 & 57.68 & 6.31 & 4.10 & 1.54 \\
\hline 2012 & 2376630.0 & 60.10 & -1.61 & 4.20 & -0.38 \\
\hline 2013 & 2299818.0 & 61.38 & -3.23 & 2.12 & -1.52 \\
\hline 2014 & 2329299.0 & 63.77 & 1.28 & 3.89 & 0.33 \\
\hline 2015 & 2420675.0 & 66.45 & 3.92 & 4.20 & 0.93 \\
\hline 2016 & 2502486.0 & 73.04 & 3.38 & 9.92 & 0.34 \\
\hline Promedio & 2049623.6 & 43.74 & 24.90 & 135.59 & 0.42 \\
\hline Arco & & & & & 0.18 \\
\hline
\end{tabular}


ECONOMÍA INFORMa | 405 | JULIO-AgOSTO 2017 |

Cuadro A3. Localización de la industria molinera de maíz en México, 2009.

\begin{tabular}{llcc}
\hline \multicolumn{1}{c}{ Estado } & Por regiones geográficas & Núm. de empresas & Porcentaje de participación \\
\hline Guanajuato & Centro & 7 & $11,1 \%$ \\
México & Centro, zona metropolitana & 7 & $11,1 \%$ \\
Michoacán & Occidente & 7 & $11,1 \%$ \\
Jalisco & Occidente & 7 & $11,1 \%$ \\
Puebla & Centro, oriente & 5 & $7,9 \%$ \\
Distrito Federal & Centro & 4 & $6,3 \%$ \\
Chihuahua & Norte, centro & 4 & $6,3 \%$ \\
Coahuila & Norte, este & 4 & $6,3 \%$ \\
Veracruz & Centro, oriente-golfo & 3 & $4,8 \%$ \\
Sonora & Norte- este & 3 & $4,8 \%$ \\
Nuevo León & Norte- este & 3 & $4,8 \%$ \\
Durango & Norte- centro & 2 & $3,2 \%$ \\
Querétaro & Centro & 1 & $1,6 \%$ \\
Aguascalientes & Centro & 1 & $1,6 \%$ \\
Hidalgo & Centro, oriente & 1 & $1,6 \%$ \\
Baja Cal. Sur & Norte, este & 1 & $1,6 \%$ \\
Guerrero & Sur & 1 & $1,6 \%$ \\
Chiapas & Sur & 1 & $1,6 \%$ \\
Yucatán & Sur, este & 1 & $1,6 \%$ \\
\hline Fuente:Pé & S & 1 & \\
\hline
\end{tabular}

Fuente: Pérez León Israel, (2010), Tesis, “El grupo Gruma uno de los principales conglomerados alimenticios en México: 1998-2007 y base constitutiva de la élite empresarial mexicana." Facultad de Economía. 
Gustavo Vargas Sánchez | El mercado de harina de maiz en México.

Una interpretación microeconómica

Cuadro A4. Capacidad instalada de las empresas y marcas en el mercado de harina de maíz mexicano en 2005.

\begin{tabular}{|c|c|c|c|c|}
\hline Empresa & Subsidiaria & Marca & Presentación & $\begin{array}{l}\text { Capacidad instalada } \\
\text { anual } \\
\text { (miles de toneladas) }\end{array}$ \\
\hline $\begin{array}{l}\text { 1. Gruma S.A.B de C.V } \\
\text { Agroinsa, S.A. de C.V. }\end{array}$ & $\begin{array}{l}\text { Maseca S.A de } \\
\text { C.V } \\
\text { Agroinsa } \\
\text { Monterrey y } \\
\text { Agroinsa Celaya }\end{array}$ & $\begin{array}{l}\text { Maseca, Mission, } \\
\text { Guerrero. } \\
\text { Agroinsa }\end{array}$ & $\begin{array}{l}\text { Regular, amarillo, tamal, } \\
\text { nixtamasa } \\
\text { Harina de maíz nixtamali- } \\
\text { zado en presentaciones de } \\
1 \mathrm{Kg} . \text {, } 10 \mathrm{Kg} \text { y } 20 \mathrm{Kg} .\end{array}$ & $\begin{array}{c}2800 \\
220\end{array}$ \\
\hline 2. Minsa S.A.B. de C.V. & - & $\begin{array}{l}\text { Minsa en } 4 \text { presen- } \\
\text { taciones (para masa, } \\
\text { tamales, maíz amarillo } \\
\text { y maíz azul) }\end{array}$ & $\begin{array}{l}\text { Masa, tamales, amarillo y } \\
\text { azul }\end{array}$ & 878 \\
\hline 3. Harimasa, S.A. de C.V. & - & Harimasa & $\begin{array}{l}\text { En función de sus granu- } \\
\text { lometrías, colores, rendi- } \\
\text { mientos, textura, suavidad, } \\
\text { resistencia y duración. }\end{array}$ & 80 \\
\hline 4. Cargill & $\begin{array}{l}\text { Cargill Foods } \\
\text { México }\end{array}$ & $\begin{array}{l}\text { Harina } \\
\text { Optimasa }\end{array}$ & $\begin{array}{l}\text { Harina de maíz para indus- } \\
\text { triales de la masa y la tortilla }\end{array}$ & - \\
\hline
\end{tabular}

Fuente: Elaboración propia con datos del Reporte anual de Minsa 2013 (p 13), y páginas web de la empresas. a) fue adquirida por Gruma en el 2005. 